\title{
Contribuição para uma política voltada à maximização da rentabilidade da Agricultura Familiar sujeito a disponibilidade relativa dos recursos e da divisão do trabalho
}

Carlos Aguedo Paiva ${ }^{1}$

\begin{abstract}
Resumo
Neste artigo, defende-se a tese de que a Agricultura Familiar e a Agricultura Patronal, no Brasil, se diferenciam pela disponibilidade relativa de mão de obra e de terras. $\mathrm{O}$ custo de mobilização de mão de obra é relativamente menor e o custo de mobilização de terras é relativamente maior para a Agricultura Familiar vis-à-vis à Patronal (e vice-versa). A partir daí, conclui-se que as atividades agropecuárias intensivas em mão de obra oferecem, normalmente, uma rentabilidade maior para a Agricultura Familiar, enquanto as atividades intensivas em terras ofereceriam maior rentabilidade de longo prazo para a Agricultura Patronal. Defende-se ainda a hipótese de que o mercado estimula a especialização dos dois Sistemas Agrários Típicos (SATs) nas atividades consistentes com as disponibilidades relativas de fatores de produção, mas o faz de forma imperfeita e marcada por path dependencies geradores de equilíbrios subótimos, nos quais atividades intensivas em trabalho (como a fruticultura da maçã e o café) são controladas pela Agricultura Patronal, enquanto produtores familiares continuam produzindo commodities intensivas em terra (como a soja). Procura-se demonstrar as hipóteses fundantes deste trabalho a partir do cálculo e da análise de correlações e regressões entre atividades produtivas e a participação dos produtores familiares no VBP e nas receitas líquidas totais da Agropecuária de 689 municípios dos três Estados do extremo sul do Brasil, em 2006 (ano do último Censo Agropecuário).
\end{abstract}

Palavras-chave: Agricultura Familiar e Agricultura Capitalista ou Patronal. Disponibilidade relativa de fatores de produção. Especialização produtiva agrícola. Equilíbrios sub-ótimos de mercado.

1 Doutor em Economia. Professor do Programa de Pós-Graduação em Desenvolvimento Regional da FACCAT e Pesquisador da Fundação de Economia e Estatística (FEE). carlosanpaiva@gmail.com 


\begin{abstract}
This paper aims to prove the thesis that family farming and capitalist farming in Brazil differ in the relative affordability of hand-labor and land. The cost of mobilizing manpower is relatively minor and the cost of mobilizing land is higher for family farming vis-à-vis the capitalist farming (and vice versa). So, those agricultural activities that use intensively manpower usually offer a larger return to family farming, while land-intensive activities are prone to offer a greater long-term profitability for capitalist farming. We also support the hypothesis that: 1) the market encourages the specialization of the two Typical Farming Systems (TFSs) in activities consistent with the relative availability of factors of production; but does so imperfectly, since any reconversion is obliterated by path dependencies that generate sub-optimal equilibrium in which labor-intensive activities (such as apple fruit and coffee) are controlled by capitalist farming, while family farmers continue to produce land-intensive commodities (like soy). We try to demonstrate our hypothesis calculating and analyzing correlations and regressions between productive activities and participation of smalIholders in the VBP and the total net proceeds of farming of 689 municipalities in three states of southern Brazil in 2006.
\end{abstract}

Keywords: Family and Capitalist Farming. Relative availability of production factors. Agriculture specialization. Sub-optimal market equilibrium.

\title{
1 A agricultura familiar pode ser intensiva em capital?
}

O sistema capitalista atribui ao mundo rural (em geral) e à produção agropecuária (em particular) um conjunto complexo e relativamente contraditório de funções, entre as quais cabe salientar: 1) Oferta de alimentos e matérias-primas industriais a baixo custo, com vistas a rebaixar o custo de reprodução de mão de obra e alavancar a rentabilidade das atividades urbanas. A depressão relativa de preços (e lucratividade) da produção agropecuária se impõe, usualmente, a partir da preservação de padrões não especificamente capitalistas de produção e de precificação no mundo rural; 2) Permitir a reprodução, ampliação e sustentação da parcela redundante do exército industrial com um mínimo de custo para o capital e para o Estado, através da produção para a subsistência da família camponesa; 3) Ampliar os espaços da valorização e da acumulação dos capitais produtivo e especulativo-imobiliário-financeiro para além das esferas especificamente urbanas, através do ingresso de empresários capitalistas na produção de alimentos e matérias-primas e pela exploração dos ganhos associados à valorização fundiária que se segue ao desenvolvimento dos sistemas de transporte e à conquista de novos mercados; e, 4) Integrar-se ao circuito interno de valorização de capital, através da consolidação do mercado rural para os mais diversos produtos industriais (fertilizantes, combustíveis, máquinas, eletrodomésticos, etc.) e serviços urbanos (saúde, educação, etc.).

Facilmente percebe-se que as duas primeiras funções são parcialmente contraditórias com as funções 3 e 4 . Essa tese é central em todo o trabalho que segue, 
essa contradição se desenvolve e se resolve das formas mais distintas em distintos países do mundo. Não se pode falar, pois, de qualquer tendência universal para o desenvolvimento da produção mercantil rural, seja no sentido de preservação de sistemas camponeses, seja no sentido de universalização agricultura empresarial, seja ainda no sentido da universalização de uma "agricultura familiar" altamente dinâmica, usuária das mais modernas tecnologias e cujo módulo rural tenderia a crescer com o desenvolvimento de padrões produtivos poupadores de trabalho vivo. Os sistemas concretos tanto podem preservar (na primeira hipótese) sua estrutura pretérita quanto convergir (nas duas outras hipóteses) para distintos padrões "modernos", ou mesmo (e esse é o ponto central) desenvolver sistemas híbridos e regionalmente diferenciados de articulação dos três "paradigmas" básicos da produção rural.

A plasticidade e a heterogeneidade dos sistemas agrários internacionais e inter-regionais assentam-se em determinações históricas complexas. Mas a sustentabilidade do heterogêneo se explica a partir de algumas particularidades técnicas das atividades agropecuárias, que vão se somar às particularidades funcionais suprarreferidas ${ }^{2}$.

As atividades produtivas e a divisão de tarefas (especialização) são definidas e circunscritas pela sazonalidade da produção agropecuária. A sazonalidade também vai impor uma grande flutuação no grau de utilização dos recursos e fatores disponíveis, resolvendo-se (no linguajar de Marx) no prolongamento do tempo de circulação do capital e na consequente depressão da taxa de lucro sobre o mesmo.

Seja porque a produção agropecuária é condição primária da vida humana, seja por sua dependência de recursos naturais (que, malgrado sua marcante heterogeneidade, são mais homogêneos que os recursos artificiais corporificados em insumos e tecnologia industriais), a produção agropecuária faz-se presente em todos os países e em todas as regiões efetivamente povoadas de cada país ${ }^{3}$. E como seus produtos são objeto de "seleção e evolução darwiniana", como todos os seres vivos, a própria natureza encarrega-se de desenvolver varietais e espécimes vegetais e raças de animais mais adequados aos distintos biomas, de forma que a produção agropecuária é incompatível com qualquer monopólio, seja ele empresarial, seja nacional ou regional.

Os produtos especificamente agropecuários são produzidos a céu aberto, e tanto os produtos nos quais um território se especializa quanto a tecnologia adotada são fortemente influenciados pelas condições edafoclimáticas (temperatura média, precipitação, padrão e profundidade do solo, etc.) do mesmo. A virtual ausência de assimetrias informacionais interempresas ${ }^{4}$ e a uniformidade qualitativa do produto conduz à rápida depressão de quaisquer "vantagens monopolistas" advindas da introdução de inovações pelos produtores diretos. De sorte que os produtos agropecuários são (malgrado exceções) commodities, que não admitem administração de preços (os produtores são tomadores de preços, que flutuam de acordo com a oferta e a demanda de mercado).

\footnotetext{
2 Em sentido estrito, as particularidades técnicas e funcionais perfazem uma unidade. As funções 1 e 2 só se preservam (a despeito de 3 e 4) dadas as particularidades técnicas da agricultura.

${ }^{3}$ O que exclui, por exemplo, o norte do Canadá e a maior parte da Groenlândia e do Alaska.

${ }^{4}$ Que é reforçada pela função 1.4: o produtor rural é literalmente assediado pelos produtos.
} 
De outro lado - e, mais uma vez, contraditoriamente -, a heterogeneidade imanente às condições edafoclimáticas e a impossibilidade de atender-se à toda a demanda mundial de alimentos e matérias-primas a partir da utilização tão somente das terras mais adequadas a cada cultivo, redundam na estruturalização da "renda da terra", por oposição às "quase rendas" urbanas, que são passíveis de superação a partir da introdução de inovações por parte das firmas concorrentes. As particularidades funcionais e técnicas das atividades rurais em geral e da produção agropecuária em particular determinam a emergência de um padrão de rentabilidade também particular nesse segmento, marcado por uma média inferior e um desvio-padrão superior ao padrão de rentabilidade (ele mesmo, heterogêneo) que caracteriza as atividades urbanas especificamente capitalistas ${ }^{5}$. Por sua vez, a particularidade do padrão de rentabilidade agropecuária vis-à-vis às demais atividades produtivas mercantis (média relativamente inferior e desvio-padrão relativamente superior) desdobra-se em uma extraordinária heterogeneidade das formas de organização fundiárias e produtivas agropecuárias compatíveis com a ordem burguesa e o desenvolvimento capitalista.

Uma plasticidade que vai se expressar na virtual impossibilidade de se identificar, classificar e teorizar o conjunto dos sistemas agrários mercantis possíveis ${ }^{6}$. Mais: se for admitido que os distintos sistemas agrários de um mesmo território nacional são solidários, de sorte que suas dinâmicas projetáveis são interdependentes, fica fácil perceber que sequer se pode analisar e sistematizar a estrutura e a dinâmica dos sistemas existentes. Os sistemas agrários efetivos são inúmeros. De sorte que qualquer tratamento teórico dos mesmos tem de ser histórico-concreto, pois, eles são, de fato e de direito, "individualidades históricas"; cada sistema agrário particular (como cada "formação econômica e social concreta") é único(a) e diferenciado(a) de todos(as) os(as) demais.

Dessa "concreticidade indeterminada"7 dos sistemas agrários não se deriva, contudo, a impossibilidade de identificação de suas leis de movimento e transformação. E isto porque a dinâmica dos distintos sistemas agrários de uma nação resulta

\footnotetext{
${ }^{5}$ Por atividades urbanas especificamente capitalistas, entende-se aquelas atividades em que a relação de produção dominante é o assalariamento formal. Isso exclui dessa categoria o conjunto das atividades urbanas informais (sejam elas lícitas, sejam ilícitas), bem como aquelas atividades cuja formalidade seja não capitalista (autoemprego, empresa individual, microempresa, cooperativas de trabalhadores, etc.). De forma mais geral, pode-se dizer que as atividades urbanas não especificamente capitalistas são aquelas desenvolvidas por indivíduos e/ou famílias e/ou organizações do segmento de reserva do exército industrial capitalista.

${ }^{6}$ Sistemas agrários mercantis são sistemas produtivos rurais que se diferenciam em função da forma como combinam um amplo conjunto de características, dentre as quais destacamse cinco: 1) estrutura de propriedade, de posse e de regulação social; 2) padrão fundiário, definido pelo tamanho médio e pelo desvio-padrão dos estabelecimentos; 3) padrões técnico-produtivos; 4) relações de trabalho e produção dominantes; e, por fim, 5) padrão de integração com o mercado e importância relativa da produção para o autoconsumo na renda global dos produtores.

7 O concreto é o particular determinado pela articulação e pela sobredeterminação de múltiplas categorias universais. Sobre "o conceito de concreto", ver Hegel (1980, p. 337).
} 
de uma única e mesma dinâmica de desenvolvimento nacional ${ }^{8}$. Vale dizer: as dinâmicas de expansão e retração (absolutas e relativas) dos distintos subconjuntos de sistemas agrários (latifundiário, empresarial, familiar, de integração capitalista, etc.) dependem, primariamente e solidariamente, da dinâmica político-econômica nacional. Chama-se a estrutura que integra funcional e dialeticamente (vale dizer: contraditoriamente e em permanente desenvolvimento) os distintos sistemas agrários de uma nação de Complexo Agrário Nacional (CAN).

A referência de cada Sistema Agrário particular a um único e mesmo CAN restringe as alternativas dinâmicas abertas à frente e viabiliza a análise das contradições e potencialidades de cada sistema agrário particular. Contudo, se a intenção é a de avaliar a própria dinâmica do CAN, faz-se necessário introduzir um novo elemento analítico, que se caracteriza por "Sistema Agrário Típico", ou SAT. O "típico", aqui, não deve ser identificado ao "tipo ideal" weberiano. Como bem nos ensinou Florestan Fernandes, todos os paradigmas sociológicos operam com "tipos", que funcionam como referências heurísticas (FERNANDES, 1980, caps. IV, V e VI da Parte II). Não obstante, o "tipo marxista" e o "tipo durkheimiano" afastam-se do "tipo weberiano" pela saturação histórica do primeiro e pela saturação empírica do segundo․

Os Sistemas Agrários Típicos (SATs) são aqueles que hegemonizam e sintetizam distintas alternativas de desenvolvimento mercantil rural e, nesse sentido, aproxima-se mais da tipologia marxista do que da weberiana e durkheimiana. De outro lado, dada a expressão empírica e política dos SATs identificados em outros estudos (e, não gratuitamente, por inúmeros analistas e pesquisadores brasileiros), não há como negar que os mesmos incorporam elementos de "tipo médio" e "tipo ideal".

Em suma: acredita-se que o CAN brasileiro pode ser caracterizado pela compatibilização dialética (vale dizer: contraditória, tensa, em permanente desenvolvimento) de dois grandes SATs: o primeiro é o que usualmente denomina-se de "agricultura familiar", o segundo é a chamada "agricultura capitalista, patronal ou empresarial"10.

Mas se for admitida a terminologia e a divisão dualista dos SATs no Brasil, caracteriza-se ambos de uma forma particular, impregnando-os de historicidade e par-

\footnotetext{
${ }^{8}$ Cabe esclarecer que não se nega a dimensão ativa das organizações responsáveis pela condução das atividades de produção e/ou do lobby político-institucional dos interesses dos distintos sistemas agrários na determinação das tendências sistêmicas. Não obstante, esses sistemas inserem-se normalmente na reprodução capitalista: como subordinados, absorvendo parcelas desproporcionalmente elevadas dos custos sociais, ecológicos e econômicos do processo de acumulação capitalista vis-à-vis aos benefícios apropriados pela integração a esse processo.

9 Idem. De acordo com Florestan, Marx se utilizaria de "tipos extremos", baseados em categorias sociais concretas que protagonizaram (a burguesia) os processos históricos transcorridos ou que, por hipótese, se habilitam a cumprir esse papel no futuro projetável (o proletariado). Já Durkheim estrutura sua análise sobre "tipos médios", identificados a categorias e estratos sociais que ocupam funções de nós articuladores e equilibradores no interior de cada estrutura social determinada. Por fim, o tipo ideal weberiano é indissociável de seu "individualismo metodológico", impondo a construção de agentes cuja ação é pautada em opções racionais de acordo com fins e/ou valores.

${ }^{10}$ Vale observar que a caracterização desses dois grandes SATs a partir do termo "agricultura" não implica qualquer subestimação da relevância da produção pecuária vis-à-vis à produção especificamente agrícola. Pelo contrário. Simplesmente adota-se aqui uma terminologia que se tornou convencional.
} 
ticularidade. Objetivamente, pretende-se que a Agricultura Familiar brasileira não se confunda, nem com a "agricultura familiar em geral" (que, de fato, não passa de uma abstração), nem com a Agricultura Familiar estado-unidense ou europeia. As particularidades dos processos de ocupação/colonização do território nacional, as especificidades de nossa transição para o capitalismo ${ }^{11}$ e o peculiar arranjo político adotado com vistas a emprestar estabilidade democrática ao sistema político-institucional no Brasil contemporâneo acabaram por maximizar a função diferenciadora de uma característica em particular sobre todas as demais que (subordinadamente) contrapõem os dois SATs. A distinção fundamental entre os dois SATs é a disponibilidade relativa de terra e de trabalho, ou, se se preferir, a relação "área por trabalhador" (Te/Tr). O que caracteriza a SAT capitalista, ou patronal, é uma grande disponibilidade de terras e a opção por sistemas técnico-produtivos poupadores de mão de obra, de sorte que a relação Te/Tr é elevada em seu interior. Diferentemente, o SAT Familiar caracteriza-se pela abundância relativa de mão de obra vis-à-vis à escassez relativa de terras.

Como já foi apontado, essa diferenciação responde a padrões históricos de ocupação do território (com base na ampla distribuição de sesmarias nos territórios economicamente mais interessantes e na colonização camponesa em regiões de fronteira, de baixa atratividade econômica), circunscrições político-institucionais contemporâneas (que limitam as possibilidades de realização de uma ampla reforma agrária) e à equação funcional das duas agriculturas no sistema econômico nacional (onde a grande propriedade se beneficia de rendas e ganhos especulativo-financeiros, e a pequena produção fornece alimentos e matérias-primas a custos relativamente deprimidos).

Infelizmente, não é possível tratar dessas amplas e complexas questões em seus mínimos detalhes neste trabalho ${ }^{12}$. Mas o que importa é tão somente entender que - dadas as limitações políticas para a implantação de uma ampla reforma agrária, as circunscrições financeiras para uma redistribuição fundiária fundada no mercado, com apoio do Estado, nos moldes de um grande Banco da Terra e os custos não desprezíveis associados ao assalariamento formal, que transcendem o dispêndio com o salário pago ao trabalhador - o CAN brasileiro consolidou um perfil dualista. Esse dualismo expressa-se nas formas mais distintas, da duplicidade de Ministérios responsáveis por cada SAT (MAPA e MDA) ao levantamento de informações no Censo Agropecuário do IBGE, passando pelos instrumentos de financiamento e assistência técnica (Pronaf, Emater, Embrapa, etc.). Mas, poder-se-ia perguntar, se caracterizar-se um SAT como "familiar" e o outro como "capitalista" (ou patronal, ou empresa(rial) não seria mais coerente pretender que o fundamento distintivo dos dois sistemas fosse a relação capital/trabalho (K/Tr), por oposição à relação terra/trabalho (Te/Tr)? Sim e não, pois a questão de fundo é o que se entende por "capital".

Quando se utiliza capital no sentido de Marx, enquanto "valor que se valoriza", a terra é capital, pois, a despeito de não ser produto do trabalho (e, portanto, a despeito de, rigorosamente, não ter valor), a capitalização da renda fundiária torna-a

\footnotetext{
${ }^{11}$ A esse respeito, ler o sétimo capítulo de Fernandes (1981) e Paiva (1992) - em especial, o capítulo oitavo.

12 Procurou-se enfrentar essa questão na Introdução de Paiva (2010, no prelo).
} 
um ativo com preço determinado e apto à valorização. Nesse sentido, ao se pautar a distinção entre os dois SATs brasileiros na relação "Te/Tr", se está, simultaneamente, diferenciando-os em termos de "K/Tr". Mais: essa é a distinção que, de fato, organiza a contraposição entre os dois sistemas. Não se cria um sistema financeiro adequado à democratização da propriedade fundiária no Brasil (assentado sobre um "Banco da Terra", densamente capitalizado e apto a trabalhar com garantias hipotecárias) justamente porque nossa fronteira agrícola em expansão, associada à modernização e à interiorização da infraestrutura viária torna a terra um ativo que cumpre as funções "precaucionais e especulativas" do dinheiro keynesiano com um mínimo de risco. Ou, se se preferir: a clivagem Te/Tr que diferencia os SATs capitalista e familiar se assenta na oposição dos padrões típicos de rendimento associados à terra e ao trabalho no Brasil: (exorbitante) valorização fictícia $X$ salário (de subsistência).

Porém, quando se toma a categoria capital em seu sentido neoclássico (e, portanto, dominante no interior da Economia), ele assume a forma de um "terceiro fator de produção". Enquanto tal, ele se consubstancia em insumos (capital circulante) e equipamentos (capital fixo) que servem de apoio ao trabalho produtivo rural. Tal como foi visto na introdução deste trabalho, uma das quatro funções da agropecuária mercantil é servir como mercado para a produção urbana de insumos. A superação da autarquia camponesa é um passo fundamental da ampliação e da consolidação do mercado interno para a produção urbana, seja ela industrial, seja de serviços. Não gratuitamente, as falhas e inconsistências de nosso sistema financeiro para aquisição de terras são amplamente compensadas por um sistema de financiamento ao custeio e ao investimento do pequeno produtor - o Pronaf - que habilita a sua "capitalização" e, por conseguinte, a ampliação de sua produtividade por unidade de área e por unidade de trabalho sem que se imponha - ou, antes: sem que se possibilite! - a expansão do módulo rural familiar.

\section{Disponibilidade relativa de recursos e especialização produtiva}

O desdobramento necessário dessa equação político-econômica é que os dois SATs brasileiros apresentam uma distinção estrutural no que diz respeito à disponibilidade relativa dos recursos Terra e Trabalho por unidade de capital (no sentido neoclássico) disponível. Para a agricultura familiar, o custo de ampliação da área cultivada não é apenas expressivo, mas, via de regra, circunscrito ao arrendamento (por oposição à aquisição). De outro lado, o custo de incorporação da mão de obra familiar é determinado pelo custo de oportunidade com o qual se deparam os jovens filhos de agricultores que ingressam no mercado de trabalho. Esse custo de oportunidade corresponde ao salário que pode obter na cidade líquido daquelas despesas adicionais (aluguel, transporte, vestuário condizente com atividades urbanas, dispêndios estritamente mercantis com alimentação, etc.), que são inerentes e exclusivas das atividades e da vida urbana. É fácil perceber que o custo de oportunidade para o jovem camponês deve ser - normalmente - inferior a um salário mínimo nacional.

Diferentemente, para o produtor capitalista, o custo do trabalho supera o salário mínimo. E isso não só (nem fundamentalmente) em função das obrigações traba- 
Ihistas que recaem sobre o empregador. Mas, acima de tudo, pelas despesas, cada vez mais frequentes, com: 1) a supervisão e fiscalização do trabalho; e com 2) despesas com honorários advocatícios e penalidades judiciais derivadas de demandas por parte dos ex-empregados ${ }^{13}$.

Ora, se o exposto acima estiver correto, se pode - e se deve - derivar todo um conjunto de desdobramentos lógico-teóricos da "estruturalização" das distintas disponibilidades relativas de recursos da agricultura familiar e patronal no Brasil. A primeira derivação é que - ao contrário do que ocorre nos EUA, onde se estruturou um sistema de financiamento da aquisição de terras de base hipotecária - a agricultura familiar brasileira é indissociável da pequena propriedade ${ }^{14}$. $E$, dado que as distribuições pessoal e funcional da renda deprimem o custo de oportunidade do assalariamento urbano para o jovem camponês brasileiro, as divergências entre os dois SATs nacionais tendem a se tornar estruturais e a induzir a - sem impor - um sistema particular de divisão do trabalho entre agricultura familiar e patronal.

O padrão de divisão do trabalho ao qual se refere aqui foi objeto de teorização no interior da Escola Neoclássica. Só que, em sua versão original, tanto a referência objetal quanto a referência territorial eram outras ${ }^{15}$. Mais especificamente, se pensa aqui no modelo Heckscher-Ohlin-Samuelson ${ }^{16}$ (doravante, HOS), segundo o qual, uma vez abertos ao comércio internacional, os países tendem a se especializar em atividades que utilizem intensamente os seus recursos mais abundantes (e, por consequência, mais baratos), importando mercadorias cuja produção é intensiva em recursos relativamente escassos (e, portanto, caros) internamente daqueles países que dispõem de maior abundância relativa dos mesmos.

De forma simplificada, o modelo postula que os países com grande disponibilidade de mão de obra (baixos salários) e recursos naturais (em especial, terra agricultável) deveriam se especializar em atividades primárias e/ou em indústrias de viés manufatureiro (intensivas em mão de obra).

Por oposição, os países que dispõem de capital e tecnologia em abundância, tenderiam a se especializar na produção de bens que utilizam relativamente pouca mão de obra e poucos recursos naturais. E a conclusão do modelo é que a especialização promove a convergência de rendimentos nos países integrados comercial-

${ }^{13}$ Como se sabe, a legislação trabalhista brasileira estrutura-se sobre o princípio de que empregados e empregadores não têm a mesma responsabilidade e obrigação de manter os registros de atividades e pagamentos realizados; de forma que, em caso de dúvida, a pena recai sobre aquele que falhou com sua obrigação de registrar adequadamente as ocorrências: o empregador.

${ }^{14}$ Evidentemente, não se está negando a existência de exceções a essa regra geral. Se pensa aqui na agricultura familiar como um "tipo", um padrão, e não como um universal que deve incorporar e subsumir toda e qualquer manifestação empírica.

${ }^{15} \mathrm{Na}$ verdade, até onde se conseguiu alcançar através da leitura de análises e interpretações de terceiros sobre a obra de Tepicht, a hipótese que se esgrimi é, na essência, a defendida por esse autor. E, se a interpretação adotada neste trabalho sobre os fundamentos da hipótese de Tepicht estiver correta, a crítica que Abramovay (2007, p. 83 e segs.) dirige à mesma é essencialmente equivocada. Não se trata de pretender que o campesinato seja incapaz de progredir tecnicamente, mas, pelo contrário, de reconhecer a sua capacidade para adaptar a tecnologia disponível às suas disponibilidades relativas de trabalho e terra.

${ }^{16}$ A esse respeito, ver Jones (1979) e Samuelson (1979). 
mente, pois a demanda por mão de obra cairá onde ela é escassa e subirá onde é abundante, enquanto, simultaneamente, movimento contrário estará ocorrendo na demanda de capital.

Da perspectiva neoclássica, o modelo HOS só é pertinente para as transações internacionais, pois as trocas que se realizam no interior de um mesmo país são caracterizadas pela livre mobilidade de trabalho, capital e tecnologia. O que implica pretender que os fatores tenham um único e mesmo preço no mercado interno, induzindo todos os empresários (que, por suposição, têm acesso a um sistema de financiamento perfeitamente eficiente) a operarem exatamente com o mesmo padrão técnico (vale dizer, com a mesma relação $\mathrm{K} / \mathrm{Tr}$, Te/Tr e K/Te).

Ora, como se sabe, Leontief demonstrou a inconsistência empírica do modelo HOS, ao revelar que os EUA exportavam mercadorias intensivas em trabalho e importavam mercadorias intensivas em capital. Deve-se a Raymond Vernon a elucidação do "paradoxo de Leontief", através de sua teoria (modestamente intitulada) do "ciclo do produto", que, na verdade, trata do padrão de investimento das multinacionais norte-americanas e europeias no mercado global ${ }^{17}$.

Mas - contraditoriamente - se o modelo HOS não é capaz de explicar a dinâmica das relações comerciais internacionais, ele pode contribuir para a compreensão do padrão de divisão do trabalho entre os dois grandes SATs brasileiros, caracterizados que são por suas distintas disponibilidades relativas de terra e trabalho.

\section{A divisão do trabalho entre os sistemas agrários familiar e patronal no Brasil}

De acordo com o modelo HOS, uma vez integrados comercialmente, os distintos países tenderiam "naturalmente" a se especializar nas atividades em que apresentam vantagens relativas. Essa trajetória "natural" - porquanto estimulada pela lógica de maximização de ganhos dos agentes empresariais - só não se imporia caso os "governos" viessem a impedir sua realização através da adoção de políticas protecionistas capazes de inibir a plena especialização dos distintos países em nichos produtivos distintos.

Ora, como os institucionalistas contemporâneos ${ }^{18}$ vieram demonstrar, a pretensão neoclássica de que o mercado pode se autoajustar de forma eficiente e virtualmente sem custos não se assenta tão somente no apelo a um "longo prazo" indeterminado (e potencialmente infinito). Mas, na abstração da existência de custos

\footnotetext{
${ }^{17}$ Sobre o "paradoxo de Leontief", ver Leontief (1983). Sobre o ciclo do produto, ver Vernon (1979).

${ }^{18}$ A especificidade do institucionalismo contemporâneo encontra-se no instrumental utilizado, que permite a formalização - através da Teoria dos Jogos e dos Custos de Transação - de fenômenos que, a despeito de fazerem parte do objeto de investigação científica no interior da Economia Política, desde (pelo menos) Adam Smith, não eram objeto de tratamento sistemático pelo mainstream. Se não se nega a relação dialética entre instrumento, clareza e determinação científica, tampouco se pode negar que os principais "dilemas" do institucionalismo moderno (prisioneiro, ação coletiva, easy-rider, stag hunt, etc.) são objeto de reflexão da filosofia política, pelo menos desde Hobbes, Hume e Rousseau, e são dimensões estruturantes da Economia Política smithiana e marxiana. A esse respeito, ver o primeiro capítulo de Paiva e Cunha (2008).
} 
de transação, assimetrias informacionais, aversão à incerteza e, last but not least, na abstração da possibilidade de equilíbrios subótimos que se preservam apenas porque a conquista de um ótimo efetivo (onde todos os agentes teriam a ganhar) não pode se dar, a não ser que todos os agentes envolvidos numa determinada cadeia de intercâmbios alterem, simultaneamente, seu padrão de inserção ${ }^{19}$.

Como se sabe, o que se deriva da crítica institucionalista ao paradigma dos mercados eficientes não é a conclusão de que os mercados são incapazes de atingir qualquer equilíbrio; nem a conclusão de que os equilíbrios subótimos sejam carentes de qualquer eficiência. Na verdade, o que se pretende é que o sistema pode ficar preso a "pontos de sela", a "máximos locais", na medida em que a trajetória histórica de constituição e estruturação dos distintos mercados impôs uma linha evolutiva que não conduz necessariamente a ótimos globais ${ }^{20}$. Em outras palavras: o que se pretende é que os mercados sejam "subeficientes". Eles são suficientemente eficientes para convergir no sentido da maximização, atingindo "máximos parciais e subótimos", mas insuficientemente eficientes para atingir "máximos paretianos".

Traduzindo a hipótese acima nos termos desta pesquisa, seria de se esperar que, dadas as diferenças de disponibilidade relativa de recursos, o Sistema Agrário Familiar apresentasse uma tendência - apenas parcialmente realizada - de especialização em ação em atividades intensivas em trabalho, enquanto o Sistema Agrário Patronal apresentaria uma tendência - igualmente inconclusa - à especialização em atividades intensivas em terra. A demonstração dessa "tendência inconclusa" é o primeiro passo de uma demonstração mais essencial: a de que a exploração do máximo rendimento possível do Complexo Agrário Nacional só pode se dar através da formulação e da adoção de políticas públicas capazes de induzir os dois SATs à plena especialização naquelas atividades mais condizentes com suas disponibilidades relativas de recursos.

Antes de passarmos à análise dos dados empíricos, com vistas a avaliar a sustentação da hipótese central, cabe um último comentário acerca da hipótese assumida neste trabalho. Buscando esclarecê-la, reproduzimos abaixo o equilíbrio para o qual - de acordo com a economia ortodoxa - um mercado caracterizado pela existência de dois grandes SATs com as características definidas aqui, acima, deveria convergir "naturalmente".

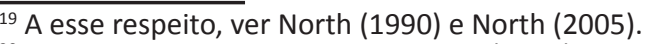

${ }^{20}$ A esse respeito, ver Nelson e Winter (1982).
} 


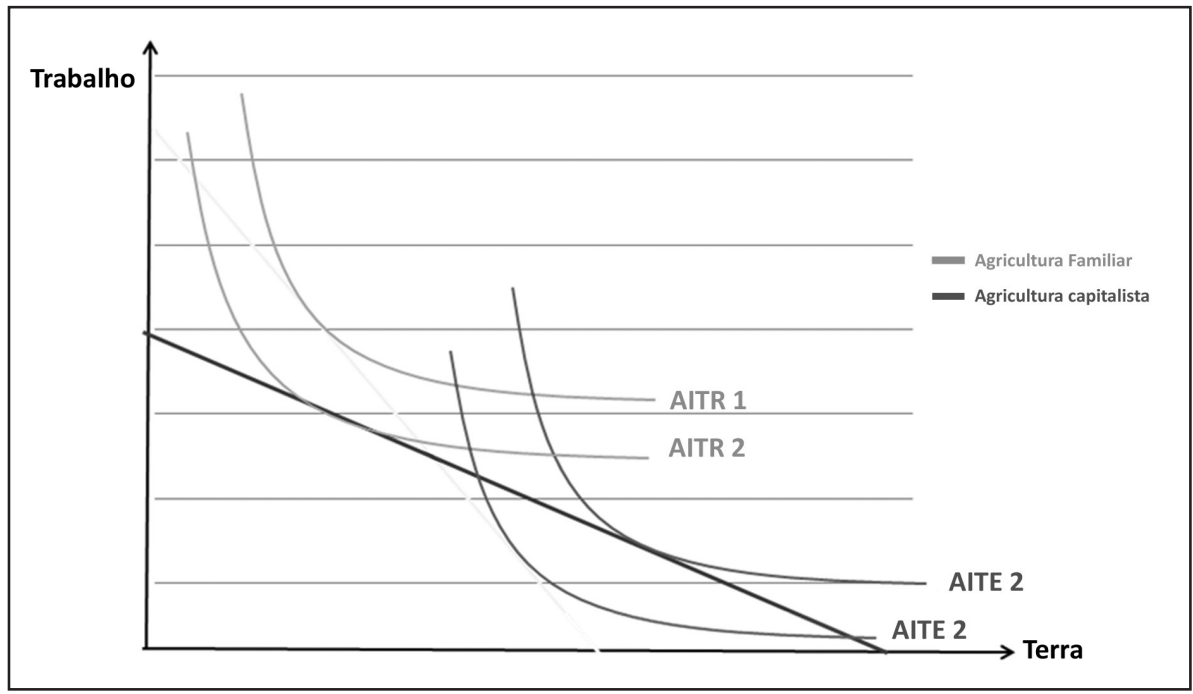

Fonte: Paiva (2009).

No Gráfico 1, representa-se duas funções de produção de atividades agropecuárias que se distinguem em função da eficiência relativa de distintas relações Te/Tr. A função "AITR" representa o conjunto das "atividades intensivas em trabaIho", enquanto a função "AITE" representa o conjunto das "atividades intensivas em terra". Dado que a Agricultura Familiar e a Agricultura Patronal (ou Capitalista) se caracterizam por apresentarem acesso a distintos volumes de terra e trabalho por unidade de capital, é possível representar essa distinção como funções "isocustos" de inclinação distinta, em um plano bidimensional onde a área (unidade de medida do fator terra) é representada na abscissa do plano cartesiano, e as horas de trabalho (unidade de medida do fator trabalho) são representadas nas ordenadas.

Se adotarmos a hipótese de que o sistema de mercado é plenamente eficiente, cada um dos SATs deveria se especializar naquelas atividades cuja função de produção (representada acima por duas isoquantas) é tangenciada pela isocusto do SAT em um patamar superior àquele que o SAT concorrente é capaz de atingir. Neste caso, cada SAT especializar-se-ia em segmentos de atividade totalmente distintos. Os dois SATs só ocupariam o mesmo nicho de atividade em situações excepcionais. Mais especificamente, isso tenderia a ocorrer somente se: 1) um dos dois SATs não fosse capaz de ofertar isoladamente a quantidade demandada da mercadoria em questão; ou 2) a função de produção de uma determinada atividade é tão flexível que SATs caracterizados por distintas disponibilidades relativas de recursos (e, por consequência, por distintas isocustos) não se diferenciam em termos de produtividade relativa, tangenciando a mesma isoquanta. 
O Gráfico 2, reproduz esta situação extrema ${ }^{21}$.

\section{Gráfico 2 - Funções de produção da Agricultura Familiar e da Agricultura Patronal}

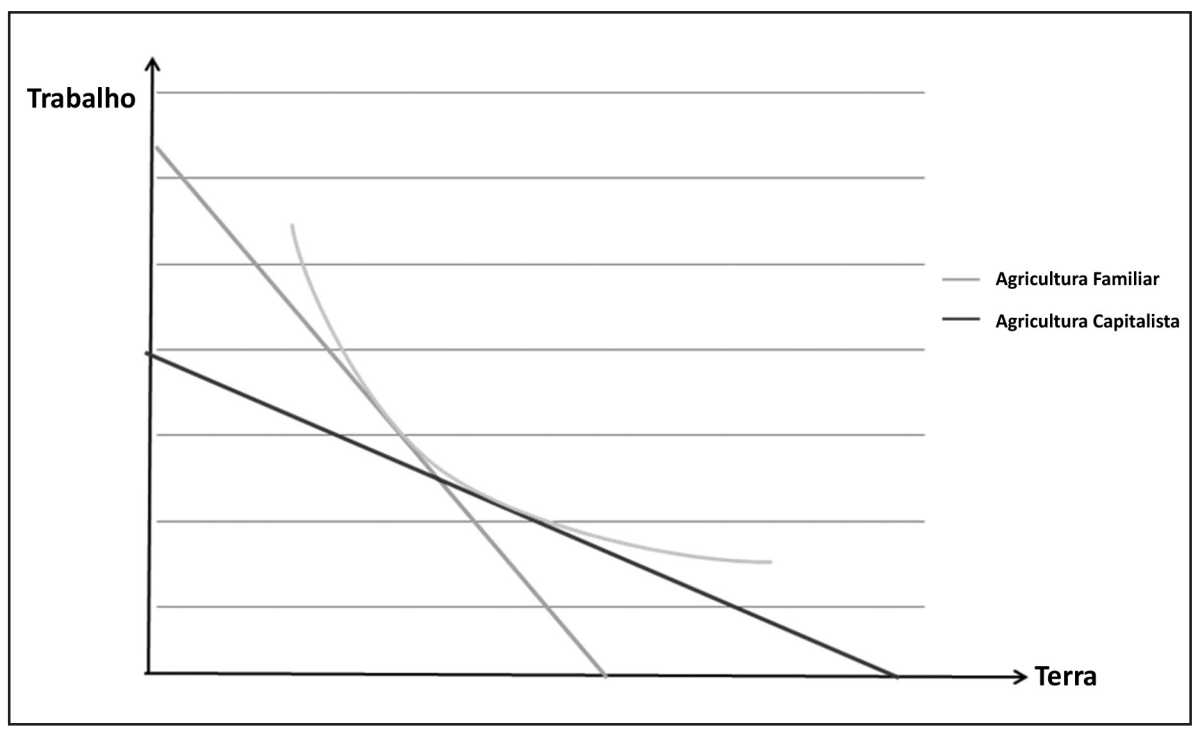

Fonte: Paiva (2009).

Não nos parece necessário esgrimir argumentos para demonstrar que: 1) as funções de produção agropecuárias apresentam flexibilidade não desprezível (pelo menos, superior à flexibilidade das funções de produção industriais, que são muito mais dependentes de recursos relativamente inflexíveis, como os sistemas de máquinas), mas raramente apresentam a flexibilidade pressuposta na representação do Gráfico 2 acima; e 2) não obstante, não se observa uma especialização produtiva tal que diferencie sistematicamente os SATs familiar e patronal no Brasil a partir de produtos e atividades virtualmente "monopolizadas" por quaisquer dos dois sistemas típicos. É bem verdade que existem algumas atividades que se associam primariamente à agricultura familiar - como a produção leiteira, a suinocultura e a avicultura -, enquanto, de outro lado, tende-se a associar a bovinocultura e a orizicultura à agricultura patronal. Não obstante, a área de intersecção parece ser muito maior do que a área propriamente especializada. Agricultores familiares e patronais atuam, simultaneamente, nas mais diversas atividades. E se alguma distinção se impõe, ela parece ser, antes, um desdobramento da "história de ocupação do mercado" (como, por exemplo, o mercado de maçã no Rio Grande do Sul, rapidamente ocupado pela

${ }^{21}$ Vale observar que as duas situações excepcionais, apontadas acima, não são rigorosamente "alternativas". Na verdade, se um dos dois SATs não fosse capaz de atender plenamente à demanda incidente sobre o conjunto dos produtos para os quais apresenta uma eficiência produtiva maior, a intersecção produtiva entre os dois sistemas tenderia a se dar naquelas atividades cuja função de produção apresenta a máxima flexibilidade possível, aproximando-se do (sem, necessariamente, se identificar ao) perfil da função de produção representada no Gráfico 2. 
agricultura patronal dos "Campos de Cima da Serra") do que por qualquer determinação associada à disponibilidade e/ou demanda relativa de fatores produtivos. O que impõe uma disjuntiva: ou está errada a hipótese levantada acima de que as distintas disponibilidades de recursos deveriam induzir a especializações igualmente distintas, ou essa hipótese, a despeito de correta, não se manifesta de forma plena, porque os mercados são apenas "subeficientes". É para o enfrentamento dessa disjuntiva que se volta agora.

\section{As especializações produtivas da agricultura familiar e da agricultura patronal nos estados do sul do Brasil}

Buscando testar a consistência da hipótese estruturante deste trabalho - vale insistir: que os dois grandes SATs do CAN brasileiro apresentam alguma divisão do trabalho, mas não aquela projetada teoricamente em função da "subeficiência" do mercado -, resgata-se um amplo conjunto de informações acerca da especialização produtiva, da estrutura fundiária e do padrão de incorporação de trabalho (familiar ou assalariado) nos 1.188 municípios que compõem os três Estados do Sul do Brasil. Optou-se por trabalhar com mais de uma fonte de informação, tendo em vista todo um conjunto de limitações dos dados recentemente divulgados do Censo Agropecuário de $2006^{22}$. Não obstante, a fonte primária de todas as informações processadas é o IBGE, o que garante um mínimo de unidade e comparabilidade para as informações selecionadas ${ }^{23}$.

O primeiro movimento foi o de definir um conjunto de variáveis "dependentes" - cujos valores busca-se explicar - e "independentes", tais que, sustentadas as hipóteses, contribuiriam para explicar o valor das "dependentes". Entre as primeiras incluímos: 1) a percentagem do VBP municipal gerado pela agricultura familiar

${ }^{22}$ Em função do caráter "declaratório" das informações censitadas, impõem-se uma tendência à subestimação de valores de ingresso e sobrestimação de despesas por parte dos declarantes, com vistas a evitar eventuais acareações com a contabilidade fiscal. O resultado é que - apenas para dar um exemplo expressivo - mais de 30 milhões de cabeças de gado bovino foram "extraviadas" entre o Censo Agropecuário (que contabilizou 171.613.337 cabeças em 2006) e a Pesquisa Pecuária Municipal (que contabilizou 205.866.244 cabeças no mesmo ano). Como se isso não bastasse, a utilização de um aparato novo e sofisticado de processamento de informações (palmtop) por parte dos recenseadores parece ter cobrado o seu preço sob a forma de um conjunto não desprezível de incongruências. Assim é que, por exemplo, dentre os 1.188 municípios dos três Estados do Sul, 203 apresentavam uma área total (que inclui a área urbana, a área das estradas e as margens de rio e lago) inferior ao somatório das áreas dos estabelecimentos rurais. Da mesma forma, 376 municípios dentre os 1.188 já referidos apresentaram um Valor Bruto da Produção Agropecuária inferior ao Valor Agregado Bruto da Agropecuária em 2006, tal como calculado pelo IBGE, em parceria com as Instituições Estaduais de Estatística (Ipardes, FEE, etc.).

${ }^{23}$ Com vistas a garantir essa consistência, extraímos de nossa população todos os municípios que apresentavam discrepâncias anormalmente elevadas entre as informações sistematizadas no Censo Agropecuário e as demais informações fornecidas pelo IBGE. O resultado da abstração das informações de menor confiabilidade foi a redução de nossa população de um total inicial de 1.188 municípios para um total de 689 municípios, que corresponde a, aproximadamente, $58 \%$ da população inicial. Os critérios utilizados para estratificação encontram-se no documento intitulado "Anexo do Projeto: A Estrutura do Complexo Agrário Nacional" disponibilizado em: http://www.territoriopaiva.com/ctms_pg/3/48/projetos_e_ rela torios_de_pesquisa/2 
(Dvbp\%af); e 2) a percentagem das Receitas Rurais Totais apropriadas pelos estabelecimentos de Agricultura Familiar (DRECfato). Caracteriza-se, ainda, todo um conjunto de variáveis como "protodependentes"; na medida em que, de um lado, também há o interesse em buscar relações funcionais que as expliquem, e, de outro, pelo fato de elas apresentarem um grau de independência teórico-formal com as "propriamente dependentes" que se permite introduzi-las em exercícios de regressão com vistas a hierarquizar os determinantes daquelas. Dentre as "protodependentes", algumas se mostraram particularmente expressivas nos inúmeros exercícios de correlação e regressão feitos até o momento, tais como: 1) população ocupada municipal total por área total dos estabelecimentos agropecuários (DpoAres); 2) percentual da população ocupada em estabelecimentos com até 100 ha (Dpo100h). Por fim, diferencia-se as independentes potenciais (muito mais numerosas) por subconjuntos. $O$ primeiro deles refere-se à participação do VBP de todo um conjunto de produtos no VAB total e/ou no VBP total do município. O segundo grupo diz respeito à participação da População Ocupada (doravante, PO) nas diversas atividades ${ }^{24}$. 0 terceiro grupo diz respeito à estrutura fundiária aparente, medida a partir de indicadores do tipo "\% da área total ocupada por estabelecimentos com até 20 ha ou com mais de 500 ha". O quarto e último grupo de variáveis independentes estrutura-se sobre informações acerca das percentagens de áreas alocadas em cada município para as distintas atividades $^{25}$.

Uma vez determinadas as variáveis dependentes, "protodependentes" e (rigorosamente) independentes, deu-se início a um conjunto de testes de correlação entre as mesmas, buscando testar a consistência das hipóteses. Alguns dos resultados mais interessantes desses testes foram reproduzidos no Anexo Estatístico, que se encontra ao final deste documento ${ }^{26}$. Dentre estes resultados, quer-se salientar os seguintes:

1 - Tal como se observa na primeira tábua de Correlações - onde se cruzam as variáveis dependentes e "protodependentes" entre si -, as participações percentuais da agricultura familiar no VBP agropecuário municipal (Dvbp\%af) e no conjunto das receitas monetárias dos estabelecimentos agropecuários (DRECfato) são positivamente, fortemente e significativamente correlacionadas às seguintes variáveis

\footnotetext{
${ }^{24}$ Vale observar que a acuidade relativa desse dado é inferior ao primeiro, pois a imputação da PO a distintas atividades é feita a partir da identificação da "atividade principal" (identificada àquela que gera a maior receita) de cada estabelecimento. Quanto mais "multifuncional" for o estabelecimento, menor acuidade haverá nesse tipo de imputação.

${ }^{25} \mathrm{~A}$ totalidade das variáveis processadas em outros trabalhos deste autor, acompanhadas do glossário, com as especificações e fontes das variáveis, bem como de todo um conjunto de exercícios de correlação e regressão entre as variáveis, com as respectivas medidas de significância, encontram-se no documento intitulado "Anexo do Projeto: Estrutura do Complexo Agrário Nacional", disponibilizado no site do autor (para link, ver nota 23).

${ }^{26}$ As diversas células das três Tábuas de Correlações foram destacadas pelo uso de cores, que têm o seguinte significado: 1) a cor verde expressa uma correlação teoricamente esperada e positiva com a participação da agricultura familiar no VBP e nas Receitas Totais; 2) a cor amarela expressa uma correlação teoricamente esperada e negativa com a mesma participação; e 3) a cor laranja expressa uma correlação discrepante com a projetada teoricamente, e que traduz a "subeficiência alocativa do mercado" no processo de indução dos dois SATs à especialização produtiva em nichos nos quais os mesmos apresentam vantagens competitivas estruturais.
} 
"protodependentes": a) população ocupada por área (DpoAres), o que corrobora a hipótese de que a agricultura familiar é relativamente abundante em mão de obra; b) percentagem da população ocupada em estabelecimentos com até 100 ha (Dpo\%100h), o que corrobora a hipótese de que, para além da maior disponibilidade relativa de trabalho, a agricultura familiar é indissociável da pequena propriedade;

2 - Tal como se observa na segunda tábua de Correlação, as duas variáveis dependentes suprarreferidas são negativamente, fortemente e significativamente correlacionadas com: a) a participação da agricultura temporária no VAB municipal; b) a participação do arroz no VAB municipal; c) a participação da soja no VAB municipal; e d) a participação da cana no VAB municipal. Vale observar que essas mesmas variáveis são negativamente correlacionadas com o indicador "PO/ ha" (população ocupada por área). Essas correlações corroboram a hipótese apresentada que a agricultura familiar apresenta desvantagens relativas frente à agricultura patronal, quando ingressa em atividades que não mobilizam seu recurso abundante (o trabalho) ao longo de todo o ano e que são altamente dependentes da área agricultável;

3 - Dentre as principais culturas temporárias, a única que apresenta uma correlação positiva com as variáveis dependentes é a cultura do fumo. Essa aparente exceção, contudo, é facilmente explicável pelo fato de que a cultura do fumo é altamente exigente em trabalho e ocupa a mão de obra por quase todo o ano, ao contrário da maior parte de cereais e leguminosas. Na verdade, tabaco, cana e algodão são culturas que se encontram numa espécie de limbo entre as lavouras temporárias e permanentes, sendo, todas, altamente demandantes de trabalho ${ }^{27}$. O que impõe o questionamento acerca da correlação negativa - sempre forte e significativa - entre cana-de-açúcar e as variáveis dependentes. Essa é uma dentre outras expressões do caráter "subeficiente" do mercado para impor uma divisão do trabalho consistente com a disponibilidade relativa de fatores de produção dos dois principais SATs nacionais;

4 - Não existe qualquer correlação expressiva, seja positiva ou negativa, entre a participação global (agregada) da lavoura permanente no VAB municipal e as variáveis dependentes. Esse fenômeno parece "se explicar" pelo fato de as diversas culturas permanentes apresentarem relações muito distintas com as percentagens de VBP e Receitas Totais apropriadas pela Agricultura Familiar. Enquanto café e maçã apresentam correlações negativas altamente significativas com essas variáveis, quanto maior a participação da laranja e da uva (bem como de "outras frutas" e da erva-mate) no VAB municipal, tanto maior a apropriação percentual de receitas pela agricultura não capitalista. Vale observar que essa "troca de sinais" se faz acompanhar de uma outra: café e maçã apresentam uma correlação negativa significativa com o indicador "PO/ha"; o contrário ocorrendo com laranja e uva. Tendo em vista que o café é, notoriamente, uma atividade intensiva em mão de obra (assim como a fruticultura em geral, inclusive a da maçã), acredita-se que essa correlação negativa se explique, antes, por determinações históricas (que levaram à ocupação de tais nichos produtivos pela agricultura patronal) do que por quaisquer determinações de ordem técnica ou de padrão de produção. Essa seria mais uma manifestação da

27 Não gratuitamente, essas culturas estiveram associadas à produção escravista e ao tráfico negreiro ao longo dos séculos XVI, XVII, XVIII e XIX. 
"subeficiência alocativa do mercado";

5 - Via de regra, os indicadores de maior comprometimento do território com a pecuária apresentam correlação positiva, forte e significativa com a apropriação relativa de receitas e geração de VBP por parte da agricultura familiar. Essa correlação varia, contudo, na razão inversa do número médio de animal e do tamanho médio da área necessária à sua reprodução. Assim, os indicadores de maior participação relativa da pecuária avícola e suína apresentam, sistematicamente, correlação positiva com as variáveis dependentes suprarreferidas. Mas apenas a bovinocultura leiteira (avaliada, tanto pela produção de leite, quanto pelo número de vacas ordenhadas, relativizados por área, VBP ou VAB) apresenta o mesmo perfil de correlação, por oposição à bovinocultura de corte (via de regra, a pasto), a equinocultura e a ovinocultura;

6 - Todos os indicadores de maior expressão econômica da silvicultura - com ênfase na produção de madeira para celulose - apresentam correlação negativa altamente significativa com as variáveis dependentes. Essas culturas também são altamente "exclusivistas", tendendo a se impor como monocultura no território. A única exceção dentre as variáveis selecionadas é a produção de madeira para móveis, que apresenta uma (discreta, mas significativa) correlação positiva com a participação da maçã no VAB municipal;

7 - Por fim, como se observa na terceira tábua de Correlações, ao contrário da maioria das lavouras temporárias - com ênfase na soja, altamente exigente em termos de área - as distintas pecuárias, bem como as distintas lavouras permanentes, são permeáveis à diversificação produtiva rural. Assim é que - por exemplo - quanto maior a participação da uva no VAB agropecuário municipal, tanto maior é a produção esperada de maçã, de mel e de suínos. As correlações positivas e estatisticamente significativas entre distintas culturas e/ou atividades agropecuárias foram destacadas com o uso da cor verde como fundo da célula. Vale observar que, dentre as diversas atividades agropecuárias, a produção de leite é aquela que parece apresentar maior solidariedade com as demais, seja em função de número, significância e magnitude de suas correlações positivas (com aves, ovos, mel e suínos), seja pelo pequeno número, insignificância e/ou baixa magnitude das eventuais correlações negativas apresentadas com outras culturas. A despeito de ser uma cultura temporária de verão - o que deveria implicar solidariedade com culturas de inverno e com outras atividades rurais de sazonalidade menos marcada -, o exclusivismo da soja é notável. Dentre as culturas que apresentam correlação positiva com a apropriação da agricultura familiar, apenas o fumo apresenta tendência comparável ao "monocultismo".

Quer nos parecer que esses testes de correlação corroborem o conjunto de hipóteses, seja no que diz respeito à eficácia relativa do mercado - demonstrada pela oposição sistemática entre os indicadores de apropriação de receitas pela agricultura familiar e pela lavoura temporária, com ênfase na soja -, seja no que diz respeito à insuficiência do mercado para garantir uma divisão do trabalho plenamente consistente com as disponibilidades relativas de recursos dos dois SATs - demonstrada pelas inúmeras "células laranja", cuja correlação empírica destoa do padrão teoricamente projetado. 
Ao permitir a operação simultânea com um número maior de variáveis bem como a hierarquização relativa das mesmas a partir da imposição de fortes restrições à incorporação de variáveis redundantes (porquanto altamente correlacionadas com variáveis já incorporadas à modelagem), os exercícios de regressão abrem-nos uma perspectiva ainda mais nítida acerca das relações entre a participação percentual da agricultura familiar na produção e apropriação de receitas e as demandas de recursos naturais e humanos por parte das distintas atividades agropecuárias. Os primeiros exercícios foram realizados dentro do método tradicional de modelagem, baseado na eleição de variáveis que apresentam correlações fortes e significativas (independentemente de serem positivas ou negativas) com a variável dependente e "imposição" do ingresso das mesmas no interior do modelo.

Esse método usualmente gera resultados insatisfatórios no plano da significância dos betas estimados, na medida em que a imposição de um conjunto de variáveis altamente correlacionadas com a variável dependente usualmente implica impor o ingresso de variáveis que apresentam, elas mesmas, elevada correlação entre si. O principal instrumento de enfrentamento desse viés é a repetição do exercício de regressão com a exclusão "passo a passo" daquelas variáveis para as quais o sistema imputa "betas" estandartizados relativamente inexpressivos e não significativos.

Quando se restringi a regredir a variável dependente "\% da agricultura familiar no VBP agropecuário municipal" com os indicadores de participação relativa da produção das principais atividades agropecuárias da Região Sul (em termos de participação no VAB regional e nacional), se obteve o modelo reproduzido abaixo como "Regressão 1". De acordo com o sistema, 50\% da participação relativa da Agricultura Familiar no VBP municipal explicam-se pela expressão relativa das seguintes atividades: soja, arroz, bovinocultura de corte, silvicultura e agricultura temporária em geral, leite, aves e fumo.

Mas os padrões de relação estabelecidos entre a especialização do município nas distintas atividades e a participação da agricultura familiar são distintos. Quanto maior for a expressão das três últimas atividades - leite, aves e fumo -, tanto maior a participação da agricultura familiar no VBP municipal. De outro lado, quanto maior a participação das cinco primeiras atividades listadas acima, tanto menor essa participação. 
Quadro 1 - Regressão 1: variáveis de especialização avaliadas pela participação do VBP das distintas atividades no VAB Municipal

\begin{tabular}{|c|c|c|c|}
\hline Variáveis & $\begin{array}{c}\text { Coeficiente Beta } \\
\text { Estandartizado }\end{array}$ & Es tatís tica t & Significância \\
\hline VBAs oja &,- 229 & $-3,930$ &, 000 \\
\hline VBAarroz &,- 133 & $-4,090$ &, 000 \\
\hline VBCboico &,- 157 & $-5,392$ &, 000 \\
\hline VBAs ilvi &,- 190 & $-6,580$ &, 000 \\
\hline VBAfumo &, 318 & 8,949 &, 000 \\
\hline VBAlavte &,- 281 & $-5,006$ &, 000 \\
\hline VBAleite &, 131 & 4,015 &, 000 \\
\hline VBCaves &, 061 & 2,071 &, 039 \\
\hline $\begin{array}{c}\text { Dependente: Part \% da Agric Fam } \\
\text { no VBP mun }\end{array}$ & R2 ajustado $=0,488$ \\
\hline
\end{tabular}

Fonte: Elaborado pelo autor com base em IBGE-SIDRA (2010).

Quando se introduzem duas variáveis que são caracterizadas como "protodependentes" - a relação entre População Ocupada (PO) e a Área Total dos Estabelecimentos, Dpoares, e a relação entre PO e VBP municipal -, o coeficiente de determinação do sistema atinge quase $60 \%$.

Quadro 2 - Regressão 2: Variáveis de especialização avaliadas pela participação do VBP das distintas atividades no VAB Municipal + PO por área

\begin{tabular}{|c|c|c|c|}
\hline Variáveis & $\begin{array}{c}\text { Coeficiente Beta } \\
\text { Estandartizado }\end{array}$ & Estatística $\mathrm{t}$ & Significância \\
\hline DpoAres &, 395 & 12,601 &, 000 \\
\hline VBAarroz &,- 044 & $-1,736$ &, 083 \\
\hline VBAsilvi &,- 122 & $-4,770$ &, 000 \\
\hline VBAfumo &, 277 & 10,417 &, 000 \\
\hline VBAlavte &,- 277 & $-9,193$ &, 000 \\
\hline VBAleite &, 097 & 3,324 &, 001 \\
\hline DpoVBP &, 094 & 3,410 &, 001 \\
\hline VBCaves &, 065 & 2,451 &, 014 \\
\hline $\begin{array}{c}\text { Dependente: Part \% da Agric Fam } \\
\text { no VBP mun }\end{array}$ & R2 ajustado $=0,598$ \\
\hline
\end{tabular}

Fonte: Elaborado pelo autor com base em IBGE-SIDRA (2010) 
Por sua vez, a introdução de apenas uma dentre os indicadores de estrutura fundiária - no caso, a participação percentual dos estabelecimentos com mais de 50 ha e menos de 100ha na área total dos estabelecimentos -, o coeficiente de determinação eleva-se discretamente, e a variável fundiária ganha proeminência sobre as demais. Tal como no caso anterior, esse resultado corrobora a indissociabilidade entre agricultura familiar, pequena propriedade e abundância de mão de obra.

Quadro 3 - Regressão 3: Variáveis de especialização avaliadas pela participação do VBP das distintas atividades no VAB Municipal + PO por área + \% da área total de estabelecimentos entre 50 e 100 ha

\begin{tabular}{|c|c|c|c|}
\hline Variáveis & $\begin{array}{c}\text { Coeficiente Beta } \\
\text { Estandartizado }\end{array}$ & Estatística t & Significância \\
\hline DpoAres &, 423 & 14,313 &, 000 \\
\hline VBAsoja &,- 115 & $-2,325$ &, 020 \\
\hline ARE50100 &, 216 & 9,132 &, 000 \\
\hline VBAarroz &,- 067 & $-2,422$ &, 016 \\
\hline VBAfumo &, 219 & 7,299 &, 000 \\
\hline VBAlavte &,- 221 & $-4,669$ &, 000 \\
\hline VBAsilvi &,- 101 & $-4,141$ &, 000 \\
\hline VBAleite &, 070 & 2,519 &, 012 \\
\hline DpoVBP &, 055 & 2,134 &, 033 \\
\hline $\begin{array}{c}\text { Dependente: Part \% da Agric Fam } \\
\text { no VBP mun }\end{array}$ & R2 ajustado $=0,639$ \\
\hline
\end{tabular}

Fonte: Elaborado pelo autor com base em IBGE-SIDRA (2010).

Na verdade, a relação entre pequena propriedade - ou, nos termos neoclássicos, entre escassez relativa de fator terra - e agricultura familiar é tão estreita que, quando se introduz um indicador mais preciso e abrangente da participação dos "pequenos estabelecimentos" na área total, o parâmetro beta da variável DpoAres inverte o seu sinal. Isso não significa - evidentemente - que a correlação entre PO por área e a participação da agricultura familiar tenha se invertido. Essa relação é inalterável e fortemente positiva. Ocorre, contudo, que a expressão relativa da pequena propriedade na área total apresenta uma correlação tão forte e tão significativa com a participação da agricultura familiar no $\operatorname{VBP}(0,835$; com sig $=0,000)$ que a DpoAres passa a ingressar no sistema como "variável compensatória", revelando que esta última variável não é uma função simples e direta da "escassez de terra e abundância de trabalho". Quanto mais democrática a estrutura fundiária municipal, tanto menor o excedente de mão de obra relativo de mão de obra na agricultura familiar e tanto menor o papel desse excedente na determinação da participação da AF no VBP municipal. 
Quadro 4 - Regressão 4: Variáveis de especialização avaliadas pela participação do VBP das distintas atividades no VAB Municipal + PO por área + \% da área total de estabelecimentos até 100 ha

\begin{tabular}{|c|c|c|c|}
\hline Variáveis & $\begin{array}{c}\text { Coeficiente Beta } \\
\text { Estandartizado }\end{array}$ & Estatís tica t & Significância \\
\hline AREat100 &, 838 & 25,883 &, 000 \\
\hline VBAsoja &,- 176 & $-7,899$ &, 000 \\
\hline DpoVBP &, 165 & 8,156 &, 000 \\
\hline VBAfumo &, 134 & 6,959 &, 000 \\
\hline DpoAres &,- 200 & $-5,966$ &, 000 \\
\hline VBAsilvi &,- 060 & $-3,226$ &, 001 \\
\hline VBAarroz &,- 053 & $-2,749$ &, 006 \\
\hline $\begin{array}{c}\text { Dependente: Part \% da Agric Fam } \\
\text { no VBP mun }\end{array}$ & R2 ajustado $=0,782$ \\
\hline
\end{tabular}

Fonte: Elaborado pelo autor com base em IBGE-SIDRA (2010).

\section{Considerações finais: o que finda e o que apenas se inicia}

Este trabalho é parte do primeiro relatório da Pesquisa "Rentabilidade por Unidade de Área e Potencial Multiplicativo das Atividades da Agropecuária Familiar na Região Sul do Brasil entre 1996 e 2006", financiada pelo IPEA (no programa denominado Pró-Redes/Censo Agropecuário) e pelo CNPq (através de Bolsa Produtividade). Mas - como já se evidencia no título do projeto suprarreferido - este é apenas o primeiro fruto de um programa de trabalho ainda em curso. Pode-se, mesmo, pretender que a maior parte do trabalho ainda esteja para ser feita. A começar pela exploração das informações do Censo Agropecuário de 2006 e pelo cotejamento com as informações do último Censo.

Não se trata, contudo, de um exercício de "estática comparativa", nem, muito menos, de uma mera descrição do que mudou e em que sentido ao longo do tempo. Se quer, isto sim, analisar e confrontar os desdobramentos de distintas "estratégias" de desenvolvimento rural sobre a dinâmica demográfica e econômica dos municípios e territórios dos três Estados do Sul. Para tanto, será preciso:

1 - mapear e regionalizar os municípios dos três Estados do Sul em função do SAT dominante e do grau de consistência entre as especializações produtivas efetivas e as disponibilidades relativas de recursos humanos e naturais por estabelecimento;

2 - diferenciar os territórios que passaram por algum processo de inflexão produtiva ao longo do tempo, identificando: a) os seus determinantes primários (reforma agrária, inflexões de demanda, mudanças no padrão de organização dos agricultores, etc.); b) a maior ou menor con- 
sistência com o movimento que seria esperado se o mercado fosse um alocador eficiente;

3 - avaliar os desdobramentos das inflexões (ou de sua ausência!) sobre a dinâmica econômica dos municípios e das regiões definidas a partir de 5.1 e 5.2 .

O ponto 5.3 é, de fato, o ponto conclusivo e o mais complexo da pesquisa. Até porque os desdobramentos que se quer avaliar são irredutíveis à "ruralidade" tomada em um plano formal. Nesse plano - onde todas as sedes municipais são identificadas ao "urbano" -, os desdobramentos mais relevantes no plano teórico-analítico são aqueles que transcendem a ruralidade. Afinal, é no plano do (formalmente) urbano que se realiza a multiplicação do emprego e da renda rural derivada das "exportações" (para fora da região) dos produtos agropecuários nos quais o território é especializado. ${ }^{28}$

\section{Referências}

ABRAMOVAY, R. Paradigmas do Capitalismo Agrário em Questão. São Paulo: Edusp, 2007.

FERNANDES, F. A Revolução Burguesa no Brasil. Rio de Janeiro: Zahar, 1981. . Fundamentos Empíricos de Explicação Sociológica. São Paulo: T.A. Queiroz, 1980.

HEGEL, G.W. Introdução à História da Filosofia. São Paulo: Abril Cultural, 1980. (Os Pensadores).

IBGE-SIDRA. Disponível em: <http://www.sidra.ibge.gov.br>. Acesso em: 10 mar. 2010.

JONES, R. W. Proporções de Fatores e o Teorema Heckscher-Ohlin.

In: SAVASINI, J. A. et al. (Orgs.). Economia Internacional. São Paulo: Saraiva, 1979.

LEONTIEF, W. Proporção de Fatores e Estruturas do Comércio Norte-Americano: nova análise teórica e empírica. In: LEONTIEF, W. A Economia do insumo-produto. São Paulo: Abril Cultural, 1983. (Os Economistas).

NELSON, R.; WINTER, S. An Evolutionary Theory of Economic Change. Cambridge: Harvard University Press, 1982.

NORTH, D. C. Institutions, institutional change and economic performance. New York: Cambridge University Press, 1990 . Understanding de Process of Economic Change. Princeton: Princeton University Press, 2005.

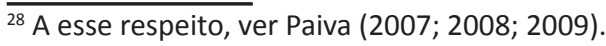


PAIVA, C. A. Capitalismo dependente e (contra) revolução burguesa no Brasil: um estudo sobre a obra de Florestan Fernandes. Dissertação (Mestrado) - Universidade Estadual de Campinas, Campinas, 1992.

. Florestan Fernandes e a Revolução Burguesa no Brasil. Santa Cruz do Sul: Edunisc, 2010. No prelo.

- O rural e o urbano no processo de regionalização com vistas à análise e ao planejamento do desenvolvimento territorial. Textos para Discussão. n. 64. Porto Alegre: Fundação de Economia e Estatística, 2009. Disponível em: <http://www.fee. tche.br/sitefee/pt/content/publicacoes/pg_tds_detalhe.php?ref=064>. Acesso em: 10 out. 2009.

. Os determinantes do aprofundamento das desigualdades territoriais no Rio Grande do Sul entre 1970 e 2000. In: PAIVA, C. A. (Org.). Evolução das desigualdades territoriais do Rio Grande do Sul. Santa Cruz do Sul: Edunisc, 2008.

Smith, Kalecki e North e os fundamentos de uma teoria geral do desenvolvimento mercantil-capitalista de regiões periféricas. In: Textos para Discussão FEE. Porto Alegre, 2007. Disponível em: <http://www.fee.tche.br/sitefee/ pt/content/publicacoes/pg_tds_detalhe.php?ref=010>. Acesso em: 10 mar. 2008

PAIVA, C. A.; CUNHA, A. M. Noções de Economia. Brasília: Fundação Alexandre de Gusmão, 2008. Disponível em: <http://www.funag.gov.br/biblioteca-digital/ manuais-do-candidato>. Acesso em: 10 maio 2009.

SAMUELSON, P. A. International factor-price equalization once again. In: Economic Journal. v. LIX, p. 245-255, jun. 1979

VERNON, R. Investimento externo e comércio internacional no ciclo do produto. In: SAVASINI, J. A. et al. (Orgs.). Economia Internacional. São Paulo: Saraiva, 1979.

\section{ANEXO ESTATÍSTICO: CORRELAÇÕES}

\section{1- Dependentes e "Protodependentes"}

\begin{tabular}{|c|r|r|r|r|r|r|}
\hline Correl & $\begin{array}{c}\text { Dvbp } \\
\% \mathrm{af}\end{array}$ & $\begin{array}{c}\text { Dpot } \\
100 \mathrm{~h}\end{array}$ & $\begin{array}{c}\text { Dpo } \\
\text { Ares }\end{array}$ & $\begin{array}{c}\text { DREC } \\
\text { fato }\end{array}$ & $\begin{array}{c}\text { DREC } \\
\text { favt }\end{array}$ & $\begin{array}{c}\text { DREC } \\
\text { fant }\end{array}$ \\
\hline Dvbp\%af & 1 &, $768^{* *}$ &, $678^{* *}$ &, $985^{* *}$ &, $927^{* *}$ &, $659^{* *}$ \\
\hline Dpot100h &, $768^{* *}$ & 1 &, $599^{* *}$ &, $749^{* *}$ &, $742^{* *}$ &, $534^{* *}$ \\
\hline DpoAres &, $678^{* *}$ &, $599^{* *}$ & 1 &, $669^{* *}$ &, $713^{* *}$ &, $406^{* *}$ \\
\hline DRECfato &, $985^{* *}$ &, $749^{* *}$ &, $669^{* *}$ & 1 &, $932^{* *}$ &, $657^{* *}$ \\
\hline DRECfavt &, $927^{* *}$ &, $742^{* *}$ &, $713^{* *}$ &, $932^{* *}$ & 1 &, $520^{* *}$ \\
\hline DRECfant &, $659^{* *}$ &, $534^{* *}$ &, $406^{* *}$ &, $657^{* *}$ &, $520^{* *}$ & 1 \\
\hline
\end{tabular}

NOTA: * Significância de 0,05

** Significância de 0,01 


\section{2 - Dependentes e Protodependentes x Independentes Selecionadas}

\begin{tabular}{|c|c|c|c|c|c|c|}
\hline Correl & $\begin{array}{c}\text { Dvbp } \\
\% \text { af }\end{array}$ & $\begin{array}{l}\text { Dpot } \\
100 \mathrm{~h}\end{array}$ & $\begin{array}{l}\text { Dpo } \\
\text { Ares }\end{array}$ & $\begin{array}{c}\text { DREC } \\
\text { fato }\end{array}$ & $\begin{array}{c}\text { DREC } \\
\text { favt }\end{array}$ & $\begin{array}{c}\text { DREC } \\
\text { fant }\end{array}$ \\
\hline VBAlavte &,$- 482^{* x}$ &,$- 369^{* *}$ &,$- 387^{* x}$ &,$- 465^{* *}$ &,$- 486^{* *}$ &,$- 209^{* * x}$ \\
\hline VBAarroz &,$- 173^{* *}$ &,$- 339^{* *}$ &,$- 167^{* *}$ &,$- 163^{* *}$ &,$- 156^{* *}$ &,$- 162^{* *}$ \\
\hline VBAcana &,$- 259^{* *}$ &,$- 355^{* *}$ &,$- 114^{* *}$ &,$- 240^{* *}$ &,$- 236^{* *}$ &,$- 183^{* *}$ \\
\hline VBAfumo &, $358^{* *}$ & $.253^{* *}$ & $289^{* *}$ & $367^{* *}$ & $.370^{* *}$ &, $159^{* *}$ \\
\hline VBAsoja &,$- 512^{* *}$ &,$- 278^{* *}$ &,$- 431^{* *}$ &,$- 509^{* *}$ &,$- 539^{* *}$ &,$- 176^{* *}$ \\
\hline VBAlavpe & 007 &,- 040 & .013 & 019 & .041 &,- 056 \\
\hline VBAcafé &,$- 105^{* *}$ &,$- 082^{*}$ &,$- 093^{*}$ &,$- 089^{*}$ &,$- 077^{*}$ &,$- 095^{*}$ \\
\hline VBAlaran & $.126^{* *}$ & .089 &, $166^{* *}$ &, $132^{* *}$ & $.154^{* *}$ &, 037 \\
\hline VBAmaçã &,$- 089^{*}$ &,$- 185^{* *}$ &,$- 126^{* *}$ &,$- 089^{*}$ &,$- 091^{*}$ &,$- 084^{4}$ \\
\hline VBAuva &, $124^{* *}$ & $.120^{* *}$ &, $111^{* *}$ &, $131^{* *}$ & $.146^{* *}$ &, 067 \\
\hline VBAmadce &,$- 164^{* *}$ &,$- 092^{*}$ &,$- 134^{* *}$ &,$- 141^{* *}$ &,$- 152^{* *}$ &,$- 124^{* *}$ \\
\hline VBAmadmo &,$- 172^{* * *}$ &,$- 142^{* *}$ &,$- 139^{* *}$ &,$- 158^{* *}$ &,$- 173^{* *}$ &,$- 083^{*}$ \\
\hline VBAproan & $249^{* *}$ &, $312^{* *}$ & $294^{* *}$ &, $233^{* *}$ & $291^{* *}$ & .010 \\
\hline VBAleite & $.331^{* *}$ & $.336^{* * *}$ & $278^{* *}$ & $330^{* *}$ & $.318^{* *}$ & $.182^{* *}$ \\
\hline VBAovos &,- 013 &, $097^{*}$ &, $156^{* *}$ &,- 038 & $.083^{*}$ &,$- 224^{* *}$ \\
\hline VBAmel & $249^{* *}$ & $204^{* *}$ &, $161^{* *}$ & $.227^{* *}$ & $.223^{* *}$ & $201^{* *}$ \\
\hline VBCsuino & $.297^{* *}$ & $.276^{* *}$ & $277^{* *}$ &, $302^{* *}$ &, $328^{* *}$ &, $154^{* *}$ \\
\hline VBCaves & $250^{* *}$ & $.237^{* *}$ & $224^{* *}$ & $261^{* *}$ & $.272^{* *}$ &, $134^{* *}$ \\
\hline VBCvacao & $.466^{* *}$ & $.426^{* *}$ & $.348^{* *}$ & $.457^{* *}$ & $.434^{* *}$ & $.328^{* *}$ \\
\hline VBCboico &,$- 173^{* *}$ &,$- 296^{* *}$ &,$- 377^{* *}$ &,$- 194^{* *}$ &,$- 246^{* *}$ &,$- 148^{* *}$ \\
\hline AREate 50 &, $831^{* *}$ &, $768^{* *}$ & $849^{* *}$ &, $823^{* *}$ & $.865^{* *}$ &, $543^{* *}$ \\
\hline ARlt $\%$ tot &,$- 179^{* *}$ &,- 002 &,- 025 &,$- 175^{* *}$ &,$- 184^{* *}$ &, 003 \\
\hline ARsoj\%to &,$- 334^{* *}$ &,$- 125^{* *}$ &,$- 224^{* *}$ &,$- 339^{* *}$ &,$- 364^{* *}$ &,$- 084^{4}$ \\
\hline ARlap\%to &, $155^{* *}$ &, $138^{* *}$ & $.210^{* *}$ &, $164^{* *}$ &, $181^{* *}$ & .064 \\
\hline ARlar\%to & $250^{* *}$ &, $198^{* *}$ & $336^{* *}$ & $.257^{* *}$ &, $284^{* *}$ &, $117^{* *}$ \\
\hline POlt $\%$ POt &,$- 077^{*}$ &,- 072 &,- 020 &,- 067 &,$- 087^{*}$ & 060 \\
\hline POfu\%tot &, $350^{* *}$ &, $256^{* *}$ & $280^{* *}$ &, $360^{* *}$ &, $357^{* *}$ &, $177^{* *}$ \\
\hline POso \%tot & $-341^{* * *}$ &,$- 158^{* *}$ &,$- 341^{* *}$ &,$- 333^{* *}$ &,$- 366^{* *}$ &,- 069 \\
\hline POlp\%tot &,$- 079^{*}$ & $-108^{* *}$ &,$- 090^{*}$ &,- 062 &,- 042 &,$- 132^{* *}$ \\
\hline POpe\%tot &, $140^{* *}$ &, $138^{* *}$ &, 068 &, $121^{* *}$ &, $117^{* *}$ &, 040 \\
\hline POsu\%pec & $217^{* *}$ &, $227^{* *}$ & $.226^{* *}$ & $227^{* *}$ &, $250^{* *}$ &, $088^{*}$ \\
\hline
\end{tabular}

NOTA: * Significância de 0,05

** Significância de 0,01 
3 - Independentes entre si

\begin{tabular}{|c|c|c|c|c|c|c|c|}
\hline & VBA layte & VBA arroz & VBA cana & VBA fumo & VBA soja & VBA lavpe & VBA cafe \\
\hline VBAlayte & 1 &, $138^{* 7}$ & $233^{ \pm 7}$ &, 054 &, $750^{47}$ &,$- 211^{m}$ &, 028 \\
\hline VBAamoz &, $138^{*}$ & 1. & $-z_{2} 069$ & 5061 &,$- 185^{* * 1}$ &,$- 097^{*}$ &,- 052 \\
\hline VBAcana & $233^{70}$ &,- 069 & 1 & $-141^{* F}$ &,- 005 &, 029 & $105^{* *}$ \\
\hline VBAfumo & 5054 &, 061 & ${ }_{5} 141^{7}$ & 1 &,$- 332^{* *}$ &,$- 142^{+7}$ &,$- 126^{*+}$ \\
\hline VBAsoja &, $750^{=}$ &,$- 185^{ \pm}$ &,- 005 &,$- 332=$ & 1 &,$- 112=$ &, 057 \\
\hline VBAlaype & $-211^{7}$ &,$- 097^{*}$ & 5029 & $-{ }_{-} 142^{7 F}$ &,$- 112^{* *+}$ & 1 & $519^{77}$ \\
\hline VBAcafé & 9028 &,- 052 & $.105^{* *}$ &,$- 126^{*=}$ & .057 & $519^{* 0}$ & 1 \\
\hline VBA1aran &,$- 168^{70}$ &,- 057 &, $100^{* *}$ &,- 056 &,$- 160^{* * 1}$ & $285^{77}$ &,- 036 \\
\hline VBAmaçã & $-144^{7-1}$ &,- 034 & $--_{2} 042$ & $--_{2} 054$ & $-.081^{*}$ & $548^{7}$ &,- 032 \\
\hline VBAHva &,$- 184^{ \pm 10}$ &,- 062 &,- 030 &,- 075 &,$- 107^{* * 1}$ & $493^{* 1+}$ &,- 010 \\
\hline VBAmadoe &,- 074 &, 044 &,- 056 &, 026 &,$- 099^{* * * 1}$ &,- 033 &,- 043 \\
\hline VBAmadmo &,$- 081^{\circ}$ &,- 019 & $-z_{7} 036$ & $--_{z} \mathbf{0 2 1}$ &,$- 077^{*}$ & , 000 & $--_{2} 017$ \\
\hline VBAproan &,$- 447^{77}$ & $-203^{\#+}$ & $-162^{* F}$ &,$- 172^{F \neq}$ &,$- 244^{* * *}$ &,$- 128^{7 F}$ &,$- 126^{* F}$ \\
\hline VBAleite &,$- 429^{\neq+}$ & $-215^{+1+}$ & $-194^{*}$ &,$- 173^{6=}$ &,$- 217^{* * * 1}$ & $-180^{A+}$ &,$- 137^{4=}$ \\
\hline VBAovos &,$- 194^{7 x=}$ &,- 066 & -5029 &,- 056 &,$- 122^{* * *}$ &, 009 &,- 051 \\
\hline VBAmel & $-315^{ \pm 0}$ &,- 061 & $-207^{*}$ &, $087^{*}$ & $-260^{* *}$ &, $078^{*}$ &,$- 140^{*}$ \\
\hline VBCsuino & $-388^{*+}$ & $-116^{*+}$ & $-128^{*}$ &,- 073 &,$- 277^{* * *}$ &,- 068 & $-.092^{7}$ \\
\hline VBCaves &,$- 331=$ &,$- 112=$ &,- 046 &,- 062 &,$- 255^{\text {***1 }}$ &,- 018 &,- 030 \\
\hline VBCracto & $-439^{+7}$ & $-190^{* 7}$ & $-192^{* 1}$ &,$- 083^{*}$ &,$- 304^{* * *}$ & $-{ }_{2} 175^{* 1+}$ &,$- 100^{* F}$ \\
\hline VBCboico &,$- 125^{-1=}$ &, $175^{* \pm}$ & 5011 &,$- 183^{*}$ &,$- 128^{* * *}$ &, 008 &, $137^{* * *}$ \\
\hline AREate50 &,$- 499^{77}$ & $-196^{77}$ & $-259^{*}$ & $250^{7 *}$ &,$- 469^{* * 1}$ &,- 006 &,$- 151^{\#+}$ \\
\hline ARlt\%tot & $592^{-7}$ &,$- 180^{-7}$ & ${ }_{2} 010$ & $-215^{-1}$ &, $700^{-1}$ & $-203=$ &,- 055 \\
\hline ARsoj\%to & $530^{70}$ & $-210^{ \pm *}$ &,- 049 & $-339^{* *}$ &, $830^{* 7}$ &,$- 159^{\# ت}$ &,- 033 \\
\hline ARlap\%to & $-209^{7=}$ &,- 070 &,- 002 &,- 015 &,$- 165^{* * * 1}$ & $672^{7}$ & $330^{*}$ \\
\hline ARlar\%to & $-265^{+0}$ &,$- 076^{*}$ &, 020 &,- 010 &,$- 230^{* *}$ & $311^{7}$ &,- 068 \\
\hline POlt\%POt & ${ }_{2}^{611^{7-0}}$ &, 030 &, 064 & $432^{F=}$ & $402^{=}$ & $-333^{-3}$ &,$- 153^{=}$ \\
\hline POfil\%tot & 055 &, $080^{*}$ & $-150^{*}$ & $947^{* 1+}$ &,$- 318^{* *}$ & $-{ }_{2} 153^{*+}$ & $-134^{* t}$ \\
\hline POso\%tot & $524^{7=1}$ &,$- 182^{* 7}$ &,- 037 & $-325^{*}$ & $820^{*-1}$ &,$- 145^{* *}$ &,- 003 \\
\hline Folp\%tot &,$- 113^{70}$ & $-{ }_{2} 018$ & $.154^{4 * *}$ & $-169^{* F}$ &,$- 081^{4}$ & ${ }_{2} 783^{47}$ & $.539^{4+4}$ \\
\hline POpe\%tot &,$- 565^{*+2}$ &,- 042 &,$- 135^{*}$ & $-384^{*}$ &,$- 350^{* *}$ &,$- 150^{* 7}$ &,$- 134^{\#+}$ \\
\hline POsu\%pec &,$- 118^{7}$ &,$- 144^{7 F}$ &,- 041 & ,059 &,$- 090^{7}$ &, 020 &,- 039 \\
\hline
\end{tabular}




\begin{tabular}{|c|c|c|c|c|c|c|c|}
\hline VBA larmm & VBA macã & VBA uFa & VBA madce & VBA madmo & VBA proan & VBA kite & VBA OrOS \\
\hline,$- 168^{7}$ & $-y_{2} 144^{7}$ & $-{ }_{2} 184^{\circ}$ &,- 074 &,$- 081^{7}$ & $-2_{2} 47^{47}$ &,$- 429^{47}$ & $-194^{77}$ \\
\hline$--_{2}, 057$ &,- 034 & $--_{2}, 062$ & ${ }_{2} 044$ &,- 019 & $-203^{* 0}$ & $-215^{*}$ &,- 066 \\
\hline, $100^{* *}$ & -042 &,- 030 &,- 056 &,- 036 & $-z_{2} 162^{70}$ & $-194^{7 F}$ &,- 029 \\
\hline$-z_{z} 056$ & $--_{z} 054$ & $--_{2} 075$ & 2026 & -021 & $-{ }_{2} 172^{*-1}$ & $-173^{7}$ &,- 056 \\
\hline,$- 160=$ &,$- 081^{x}$ &,$- 107=$ &,$- 099^{-1}$ & $-077^{x}$ & $-244^{=0}$ & $-217^{\#}$ & $-122^{=}$ \\
\hline $285^{7+}$ & $5^{548^{7}}$ & ${ }_{2} 493^{7-1}$ & -0033 & $z_{2} 000$ & $-{ }_{2} 128^{7+}$ &,$- 180^{7 F}$ & 5009 \\
\hline,- 036 &,- 032 &,- 010 &,- 043 & -5017 &,$- 126^{*}$ &,$- 137^{*}$ &,- 051 \\
\hline 1 &,- 044 &, 068 &,- 058 &,- 058 &, 018 &,- 053 & 5071 \\
\hline$-z_{2} 044$ & 1 & $.090^{*}$ & ${ }_{2} 065$ & $.097^{*}$ &,$- 085^{*}$ & $-104^{*}$ & -011 \\
\hline, 068 &, $090^{*}$ & 1 &,- 040 & -3044 &,- 005 &,- 034 &, 043 \\
\hline,- 058 &, 065 & $-_{2} 040$ & 1 & ${ }_{2} 549^{7=1}$ & $-077^{*}$ &,$- 113^{7 *}$ & 5025 \\
\hline$--_{2} 058$ &, $097^{4}$ & $--_{2} 044$ & $549^{4+1}$ & 1 & $-{ }_{7} 048$ &,$- 132^{t+}$ &, $101^{\text {nt. }}$ \\
\hline, 018 & $-{ }_{2} 085^{*}$ & $--_{2} 005$ & $--_{2} 077^{7}$ &,- 048 & 1 &, $832^{\text {*Nk }}$ &, $635^{*+1}$ \\
\hline$--_{2} 053$ &,$- 104^{n+4}$ & $--_{2} 034$ &,$- 113^{+4}$ &,$- 132+4$ & $832^{n+1}$ & 1 & $107^{*+1}$ \\
\hline 5071 & -011 & .043 &, 025 &, $101^{* * *}$ &, $635^{* * *}$ &, $107^{* * * *}$ & 1 \\
\hline, 064 &, $155^{\text {** }}$ &, $090^{*}$ &,- 002 &, 028 &, $187^{\text {** }}$ &, $164^{\text {*t: }}$ & $.086^{*}$ \\
\hline$--_{2} 041$ & -038 & 2026 & -040 & -050 & $342^{\text {**A }}$ & $368^{\text {** }}$ &, $112^{* *}$ \\
\hline,- 015 &,- 046 &, $080^{*}$ &,- 046 & ,016 &, $355^{\text {**t }}$ & $280^{\text {*t: }}$ & $247^{* * t}$ \\
\hline,- 013 & $-y^{114^{* *}}$ &,- 073 & $-{ }_{2} 135^{*+}$ & $-2124^{*+1}$ & $484^{\text {*** }}$ &, $616^{* * *}$ &, 008 \\
\hline,- 026 & $=035$ &,$- 108^{* 1}$ &,- 015 & ,005 &,- 061 &,- 034 &,$- 103^{\text {twet }}$ \\
\hline, $173^{n+1}$ &,$- 146^{7+1}$ &, $172^{17}$ &,$- 151^{n+}$ &,$- 177^{* 7}$ &, $355^{*+1}$ & $386^{* * *}$ &, $115^{k+t}$ \\
\hline$-119^{+7}$ & $-152^{*}$ & $--_{2} 100^{\circ}$ & $-{ }_{-2} 158^{-1}$ & $-{ }_{2} 154^{*}$ &,- 062 & $--_{2} 011$ &,- 072 \\
\hline,$- 126^{*+}$ &,$- 093^{ \pm}$ &,$- 102^{* \pm}$ &,$- 134^{* 1+}$ &,$- 129^{* \theta}$ &,$- \mathbf{1 0 0}$ &,- 047 &,$- 095^{*}$ \\
\hline $3^{317^{*}}$ & $s_{2} 035$ & ${ }_{2} 406^{*+=}$ & $--_{2}, 028$ & ,015 &,- 053 &,$- 119^{*}$ &, 067 \\
\hline $825^{* 1+}$ & $-z_{z} 051$ &, $142^{\text {**t }}$ &,- 060 & -073 &, $080^{\circ}$ & 031 &, $083^{4}$ \\
\hline$-{ }_{3} 182^{=}$ & $-158^{\prime}=$ & $-200^{=1}$ &,- 030 & -027 &,$- 380^{* * *}$ &,$- 334^{\text {**:F }}$ &,$- 186^{\text {**at }}$ \\
\hline$-{ }_{2} 069$ & $-z_{2} 053$ &,- 073 & 2029 & ,004 &,$- 173^{\text {**t }}$ &,$- 156^{* * t}$ &,$- 080^{7}$ \\
\hline,$- 127^{*}$ &,$- 089^{\circ}$ &,$- 091^{*}$ &,$- 123=$ &,$- 122^{n-1}$ &,$- 176^{\text {**: }}$ &,$- 134^{\text {䊝 }}$ &,$- 112^{* * 1 * t}$ \\
\hline 2227 & $274^{* 7}$ & ${ }_{2} 461^{* *}$ & $--_{2} 019$ & ${ }_{2} 018$ & $--_{2} 144^{47}$ & $-200^{7 \neq}$ & 5001 \\
\hline , 007 & $--_{2} 018$ & $-{ }_{2}, 067$ & -010 &,- 014 & $527^{* t+}$ & $537^{+1+}$ &, $173^{\#+}$ \\
\hline$-_{2} 042$ & $--_{3} 051$ &, $107^{* * 1}$ &,- 060 &,- 067 & ${ }_{2} 133^{7}$ &, $150^{7 F}$ &, 048 \\
\hline
\end{tabular}

NOTA: * Significância de 0,05

** Significância de 0,01 


\begin{tabular}{|c|c|c|c|c|c|c|c|c|}
\hline & VBAmel & VBC suino & VBC aves & VBC vacao & VBC boico & ARE ate50 & Arl \%tot & Arsoj \%to \\
\hline VBAlavte & $-315^{7+}$ & $-388^{*}$ & $-331^{7}$ & $-439^{7=}$ &,$- 125^{* *}$ & $-499^{77}$ &, $592^{7=}$ & $530^{7}$ \\
\hline VBAarroz &,- 061 & $-116^{* 1}$ & $-112^{70}$ & $-190^{* 7}$ &, $175^{* *}$ & $-196^{47}$ & $-180^{7}$ & $-210^{75}$ \\
\hline VBAcana & $-207^{77}$ &,$- 128^{* 7}$ &,- 046 &,$- 192^{7 F}$ &, 011 & $-259^{77}$ & 2010 &,- 049 \\
\hline VBAfimo &, $087^{7}$ &,- 073 &,- 062 &,$- 083^{2}$ &,$- 183^{70}$ &, $250^{7}$ & $-215^{*}=$ & $-339^{77}$ \\
\hline VBAsoja & $-260^{-7}$ & $-277^{-7}$ & $-255^{-7}$ & $-304^{-1}$ &,$- 128=$ & $-469^{-7}$ &, $700^{-7}$ &, $830^{=7}$ \\
\hline VBAlavpe & ${ }_{2} 078^{x}$ &,- 068 &,- 018 & $-175^{n}$ &, 008 &,- 006 & $-203^{7}$ &,$- 159^{71}$ \\
\hline VBAcafé &,$- 140^{ \pm=}$ &,$- 092^{2}$ &,- 030 &,$- 100^{n=}$ &, $137^{* *}$ & $-151^{* 1}$ &,- 055 &,- 033 \\
\hline VBAlaran &, 064 &,- 041 &,- 015 & -013 &,- 026 &, $173^{7}$ &,$- 119^{*}$ &,$- 126^{7}$ \\
\hline VBAmaçā &, $155^{* *}$ &,- 038 &,- 046 &,$- 114^{* 1+}$ &, 035 &,$- 146^{40}$ &,$- 152^{* 1}$ & $--_{2} 093^{*}$ \\
\hline VBAnva &, $090^{*}$ & ,026 &, $080^{*}$ &,- 073 &,$- 108^{*}$ &, $172^{7}$ & $-100^{\circ}$ &,$- 102^{F}$ \\
\hline VBAmadce &,- 002 &,- 040 &,- 046 &,$- 135^{* 7}$ &,- 015 & $-151^{70}$ & $-158^{* 7}$ &,$- 134^{F}$ \\
\hline VBAmadmo &, 028 &,- 050 &, 016 &,$- 124^{*}$ &, 005 & $-177^{77}$ &,$- 154^{*}$ &,$- 129^{7}$ \\
\hline VBAproan &, $187^{* *}$ &, $342^{* *}$ &, $355^{\text {*** }}$ &, $484^{* *}$ &,- 061 & $355^{7}$ & $--_{2} 062$ &,$- 100^{F}$ \\
\hline VBAleite &, $164^{* *}$ &, $368^{* *}$ &, $280^{* *}$ &, $616^{* *}$ &,- 034 & ,386 &,- 011 &,- 047 \\
\hline VBAovos &, $086^{*}$ &, $112^{* *}$ & $247^{* *}$ &, 008 &,$- 103^{7 \theta}$ &, $115^{7+1}$ &,- 072 & $-095^{*}$ \\
\hline VBAmel & 1 &, $112^{* *}$ &, $116^{* *}$ & $104^{* *}$ &, 000 & $218^{7}$ & $-205^{7}$ &,$- 190^{77}$ \\
\hline VBCsmino &, $112^{* *}$ & 1 &, $404^{* *}$ & $344^{* *}$ &,$- 116^{* 7}$ &, $381^{7}$ & $-126^{* 7}$ & $-222^{7}$ \\
\hline VBCaves &, $116^{* *}$ &, $404^{* * *}$ & 1 & $230^{* *}$ &,- 062 &, $301^{-1}$ & $-165^{-7}$ & $-246^{7}$ \\
\hline VBCvacao &, $104^{* 4}$ & $344^{* *}$ &, $230^{*+1}$ & 1 &, $123^{* *}$ & $475^{+0}$ & $-159^{\circ}$ & $-206^{7}$ \\
\hline VBCboico &, 000 &,$- 116^{* *}$ &,- 062 &, $123^{* *}$ & 1 &,$- 400^{7}$ & $-427^{* 1}$ & $-302^{F}$ \\
\hline AREate50 & $218^{* *}$ &, $381^{\text {** }}$ &, $301^{* *}$ &, $475^{* *}$ &,$- 400^{*}$ & 1 &,- 059 & $-244^{F}$ \\
\hline ARlt\%tot & $-205^{40}$ &,$- 126^{* *}$ &,$- 165^{* 4}$ & $-159^{* 0+}$ &,$- 427^{-4}$ &,- 059 & 1 & $889^{7}$ \\
\hline ARsoj\%to &,$- 190^{*-1}$ & $-222^{* *}$ & $-246^{*}$ & $-206^{*}$ & $-302=$ & $-244^{* 1}$ &, $889^{\circ}$ & 1 \\
\hline ARlap\%to &,- 020 &, 031 & ${ }_{2} 089^{*}$ & $-124^{* 7}$ &,$- 121^{* 1}$ & $204^{7+1}$ & $-150^{*}$ &,$- 182^{F+}$ \\
\hline ARlar\%to &, 073 &, $083^{*}$ &, $085^{*}$ &, 044 &,$- 127^{* 7}$ &, $337^{7+1}$ &,$- 139^{*}$ &,$- 191^{*}$ \\
\hline POlt\%POt &,$- 124^{* *}$ &,$- 331^{* *}$ &,$- 355^{* *}$ &,$- 338^{* *}$ & $-396^{* 1}$ & $-113^{* 1}$ &, $483^{7=}$ &, $422^{75}$ \\
\hline POfn\%tot &, 065 &,$- 077^{*}$ &,- 066 &,$- 080^{*}$ & $-200^{*}$ &, $240^{-7}$ & $-186^{-1}$ & $-323^{=}$ \\
\hline POso\%tot &,$- 168^{* *}$ &,$- 251^{* *}$ &,$- 242^{* *}$ &,$- 257^{* *}$ & $-269^{7}$ & $-300^{7+7}$ &, $715^{* 7}$ & $852^{77}$ \\
\hline POlp\%tot &,- 055 &,$- 084^{*}$ & ,008 &,$- 197^{* *}$ &, $106^{* *}$ & $-105^{* 7}$ & $-233^{* A}$ &,$- 195^{F}$ \\
\hline POpe\%tot & $131^{-}$ & $428^{-1}$ & $395^{-1}$ & $549^{-7}$ & 385 &, $178^{-1}$ & $-319^{-1}$ & $-284^{5}$ \\
\hline POsu\%pec & $2089^{2}$ &, $649^{70}$ & $201^{7}$ & ,038 & $-312^{77}$ & ,299" &, 065 &,- 049 \\
\hline
\end{tabular}




\begin{tabular}{|c|c|c|c|c|c|c|c|}
\hline Adlap \% to & Adlar \% to & Polt \%POt & Pofn \%tot & Poso \%tot & Polp \%tot & Pope \%tot & Posu \%pec \\
\hline$-209^{7}$ & $-265^{77}$ &, $611^{77}$ & ,055 & $524^{77}$ &,$- 113^{*}$ & $-565^{7}$ & $-118^{* 7}$ \\
\hline,- 070 &,$- 076^{7}$ &, 030 & $2080^{2}$ &,$- 182^{7}$ &,- 018 &,- 042 &,$- 144^{\prime \prime}$ \\
\hline,- 002 &, 020 &, 064 &,$- 150^{7}$ &,- 037 &, $154^{7}$ &,$- 135^{7}$ &,- 041 \\
\hline,- 015 &,- 010 &, $432^{* 7}$ & $947^{*}$ &,$- 325^{* *}$ & $-169^{*}$ & $-384^{7}$ & ,059 \\
\hline$-165^{\circ}$ & $-230^{=}=$ &, $402^{-1}$ & $-318^{-1}$ & ${ }_{,} 820^{-7}$ & $-081^{*}$ & $-350^{-7}$ &,$- 090^{\circ}$ \\
\hline , $672^{17}$ & $311^{71}$ & $-333^{n}$ & $-{ }_{2} 153^{71}$ &,$- 145^{11}$ & $783^{11}$ &,$- 150^{7}$ &, 020 \\
\hline $330^{-7}$ &,- 068 &,$- 153^{* 17}$ &,$- 134^{*}$ &,- 003 & $539^{* 1}$ &,$- 134^{\prime \prime}$ &,- 039 \\
\hline $317^{7}$ & $825^{* 7}$ &,$- 182^{\#-1}$ &,- 069 &,$- 127^{\#}$ & $227^{*}$ &, 007 &,- 042 \\
\hline, 035 &,- 051 &,$- 158^{* 1}$ &,- 053 &,$- 089^{2}$ & $274^{* 17}$ &,- 018 &,- 051 \\
\hline $406^{77}$ &, $142^{* *}$ & $-200^{*}$ &,- 073 &,$- 091^{*}$ & $461^{*}$ &,- 067 &, $107^{* *}$ \\
\hline,- 028 &,- 060 &,- 030 &, 029 & $-123^{*}$ &,- 019 &,- 010 &,- 060 \\
\hline, 015 &,- 073 &,- 027 &, 004 &,$- 122^{7}$ &, 018 &,- 014 &,- 067 \\
\hline,- 053 &, $080^{*}$ & $-380^{* 7}$ &,$- 173^{*}$ &,$- 176^{* 7}$ &,$- 144^{* F}$ &, $527^{\circ 7}$ &, $133^{* *}$ \\
\hline,$- 119^{7-1}$ &, 031 & $-334^{* 7}$ &,$- 156^{* 7}$ &,$- 134^{*}$ & $-200^{*}=$ &, $537^{* 7}$ &, $150^{* *}$ \\
\hline, 067 &, $083^{*}$ & $-186^{71}$ & $-080^{7}$ & $-112^{n}$ &, 001 & $173^{n}$ &, 048 \\
\hline,- 020 &, 073 &,$- 124^{* 1}$ &, 065 &,$- 168^{7}$ &,- 055 &, $131^{7}$ &, $089^{*}$ \\
\hline, 031 &, $083^{*}$ & $-331^{* 7}$ &,$- 077^{*}$ & $-251^{7}$ &,$- 084^{*}$ & $428^{7}$ &, $649^{* *}$ \\
\hline, $089^{7}$ &, $085^{*}$ & $-355^{*}$ &,- 066 & $-242^{-1}$ &, 008 & $395^{-7}$ & $201^{* * *}$ \\
\hline,$- 124^{71}$ &, 044 & $-338^{* 1}$ &,$- 080^{\circ}$ & $-257^{+1}$ &,$- 197^{*}$ & $549^{7+1}$ &, 038 \\
\hline,$- 121^{\#}$ &,$- 127^{* *}$ & $-396^{* 1}$ & $-200^{*}$ & $-269^{7}$ &, $106^{7=}$ & $385^{4}$ & $-312^{*}$ \\
\hline $204^{77}$ & $337^{* 7}$ &,$- 113^{7 F}$ & $240^{=}$ & $-300^{7}$ &,$- 105^{*}=$ &, $178^{7}$ & $299^{\prime \prime}$ \\
\hline,$- 150^{7}$ & $-139^{* 1}$ &, $483^{* 1}$ & $-186^{* 1}$ &, $715^{* 1}$ & $-233^{*}$ & $-319^{7-1}$ &, 065 \\
\hline,$- 182^{7-1}$ &,$- 191^{*}$ & ${ }_{3} 422^{-10}$ & $-323^{*+1}$ &, $852^{* 17}$ &,$- 195^{* *}$ & $-284^{A 1}$ &,- 049 \\
\hline 1 & $489^{* 7}$ & $-249^{* 7}$ &,- 019 & $-169^{7}$ & ${ }_{2} 620^{*}$ & $-{ }_{2} 145^{*}$ &, $130^{* *}$ \\
\hline $489^{7}$ & 1 & $-232^{* 1}$ &,- 017 &,$- 187^{*}$ & $267^{* *}$ &, 040 &, $080^{*}$ \\
\hline$-249^{7}=$ & $-232^{*}=$ & 1 & $476^{*=}$ &, $478^{*}$ & $-411=$ &,$- 793^{*}$ &,- 067 \\
\hline,- 019 &,- 017 & $.476^{*}$ & 1 & $-324=$ & $-186=$ & $-413^{=}$ &, 050 \\
\hline,$- 169^{77}$ &,$- 187^{* F}$ &, $478^{7}$ & $-324^{* 7}$ & 1 &,$- 172^{*}$ & $-361^{77}$ &,- 068 \\
\hline, $620^{7}$ & $267^{* 7}$ &,$- 411^{* 4}$ & $-186^{*}$ &,$- 172^{* A}$ & 1 & $-169^{f-1}$ &,- 027 \\
\hline,$- 145^{\circ}$ &, 040 & $-793^{*}$ & $-413=$ & $-361^{*}$ & $-169^{*-}$ & 1 &, $088^{*}$ \\
\hline , $130^{7}$ & $.080^{*}$ &,- 067 &, 050 &,- 068 &,- 027 & $2088^{7}$ & 1 \\
\hline
\end{tabular}

NOTA: * Significância de 0,05

** Significância de 0,01 